\title{
The serotonin hallucinogen 5-MeO-DMT alters cortico-thalamic activity in freely moving mice: regionally-selective involvement of $5-\mathrm{HT}_{1 \mathrm{~A}}$ and $5-\mathrm{HT}_{2 \mathrm{~A}}$ receptors
}

Maurizio S. Riga PhD ${ }^{1,2,3^{*}}$, Laia Lladó-Pelfort $\operatorname{PhD}^{1,2,3^{*}}$, Francesc Artigas $\mathrm{PhD}^{1,2,3}$, Pau Celada PhD ${ }^{1,2,3}$

${ }^{1}$ Department of Neurochemistry and Neuropharmacology, Institut d'Investigacions Biomèdiques de Barcelona, CSIC-IDIBAPS

${ }^{2}$ CIBERSAM (Centro de Investigación Biomédica en Red de Salud Mental) ${ }^{3}$ Institut d'Investigacions Biomèdiques August Pi i Sunyer (IDIBAPS)

*The first two authors contributed equally to the study

Corresponding author: Pau Celada, PhD; Dept. of Neurochemistry and Neuropharmacology, IIBBCSIC (IDIBAPS), Rosselló, 161, $6^{\text {th }}$ floor, 08036 Barcelona, Spain. Phone: + 3493-363 8314; Fax: + 3493-363 8301; e-mail: pau.celada@iibb.csic.es

Number of pages: 31

Number of figures: 7

Number of Tables: 1

Supplementary information: 1 figure and 4 Tables

Number of words: abstract: 250 words; introduction: 904 words

Full manuscript: 5164 words (excluded abstract and references)

Key words: 5

Figures: (cm) 9 (1 column); 140 mm ( 1 column and half); 190 ( 2 column) max with $22 \mathrm{~cm}$ high 


\begin{abstract}
5-MeO-DMT is a natural hallucinogen acting as serotonin $5-\mathrm{HT}_{1 \mathrm{~A}} / 5-\mathrm{HT}_{2 \mathrm{~A}}$ receptor agonist. Its ability to evoke hallucinations can be used to study the neurobiology of psychotic symptoms and to identify new treatment targets. Moreover, recent studies revealed the therapeutic potential of serotonin hallucinogens in treating mood and anxiety disorders. Our previous results in anesthetized animals show that 5-MeO-DMT alters cortical activity via 5- $\mathrm{HT}_{1 \mathrm{~A}}$ and $5-\mathrm{HT}_{2 \mathrm{~A}}$ receptors.

Here, we examined 5-MeO-DMT effects on oscillatory activity in prefrontal (PFC) and visual (V1) cortices, and in mediodorsal thalamus (MD) of freely-moving wild-type (WT) and 5- $\mathrm{HT}_{2 \mathrm{~A}}-\mathrm{R}$ knockout (KO2A) mice. We performed local field potential multi-recordings evaluating the power at different frequency bands and coherence between areas. We also examined the prevention of 5-MeO-DMT effects by the $5-\mathrm{HT}_{2 \mathrm{~A}}-\mathrm{R} / \mathrm{D}_{2}-\mathrm{R}$ blocker risperidone and the $5-\mathrm{HT}_{1 \mathrm{~A}}-\mathrm{R}$ antagonist WAY-100635.

5-MeO-DMT affected oscillatory activity more in cortical than in thalamic areas. More marked effects were observed in delta power in $\mathrm{V} 1$ of KO2A mice. 5-MeO-DMT increased beta band coherence between all examined areas. In WT mice, risperidone prevented only 5-MeO-DMT effects in mPFC-theta band and in mPFC-MD theta and beta coherences. In KO2A mice, WAY100635 prevented most of 5-MeO-DMT effects on oscillatory activity.

The present results indicate that hallucinatory activity of 5-MeO-DMT is likely mediated by simultaneous alteration of prefrontal and visual activities. The prevention of these effects by WAY100635 in KO2A mice supports the potential usefulness of $5-\mathrm{HT}_{1 \mathrm{~A}}$ receptor antagonists to treat visual hallucinations. 5-MeO-DMT effects on PFC theta activity and cortico-thalamic coherence may be related to its antidepressant activity.
\end{abstract}

Hightlights (5): (85 characters including spaces) SOBRA UNA

5-MeO-DMT alters cortico-thalamic activity more in MPFC and V1 than MD thalamus. 
5-MeO-DMT augments beta band coherence between cortico-thalamic areas.

5-HT $T_{2 A}-R$ blockade does not prevent all 5-MeO-DMT effects in WT mice.

5-HT $T_{1 A}-R$ antagonism avoids 5-MeO-DMT actions in KO2A mice.

5-MeO-DMT increases more markedly V1 delta power of KO2A mice

Increase in PFC theta band by 5-MeO-DMT may be related to its antidepressant effect

Keywords (5): serotonin hallucinogens, 5-MeO-DMT, cortico-thalamic activity, 5- $\mathrm{HT}_{1 \mathrm{~A}}$ receptor, 5$\mathrm{HT}_{2 \mathrm{~A}}$ receptor 


\section{Introduction}

5-Methoxy- $\mathrm{N}, \mathrm{N}$-dimethyltryptamine (5-MeO-DMT) is a natural serotonergic hallucinogen found in a variety of plant mixtures (e.g., Virola snuffs) and in the Sonoran desert toad venom, Bufo alvarius, used in ritual ceremonies and for healing and recreational purposes (McKenna, 2004; Shen et al., 2010). The serotonergic hallucinogens evoke changes in perception, thought, mood and cognition (Nichols, 2004). Some of these agents were marketed in the past as a therapeutic aid in psychoanalysis and, more recently, several studies support their use in the treatment of psychiatric disorders, mostly mood and anxiety disorders (Carhart-Harris et al., 2016a; McKenna, 2004; Vollenweider and Kometer, 2010). In this context, there is an increasing interest to understand the neurobiological changes and mechanisms that occur during the psychedelic experience. Moreover, psychedelic agents are used to model certain aspects of psychosis in experimental research (Geyer and Vollenweider, 2008), helping also to identify brain circuits altered in psychiatric disorders (Vollenweider et al., 1997).

Structurally, the serotonergic hallucinogens are divided in two main classes: a) indoleamines such as lysergic acid diethylamide (LSD), psilocin, psilocybin, $\mathrm{N}, \mathrm{N}$-dimethyltryptamine (DMT) and 5-MeODMT which bind with high affinity to several $5-H T$ receptors (5-HT-R), namely $5-H T_{1 A}-R, 5-H T_{2 A}-R$ and 5-HT2C-R (McKenna et al., 1990; Sills et al., 1984) and, b) phenylalkylamines such as mescaline and 2,5-dimethoxy-4-iodoamphetamine (DOI) which are highly selective for $5-\mathrm{HT}_{2 \mathrm{~A}} \mathrm{R}$ and $5-\mathrm{HT}_{2 \mathrm{C}} \mathrm{C}$ (McKenna and Peroutka, 1989). Preclinical and clinical evidence support that the psychotomimetic action of these hallucinogens is, at least, partially mediated by their agonistic actions at cortical 5$\mathrm{HT}_{2 \mathrm{~A}}-\mathrm{R}$ (Gonzalez-Maeso et al., 2007; Nichols, 2004).

$5-\mathrm{HT}_{1 \mathrm{~A}}-\mathrm{R}$ and $5-\mathrm{HT}_{2 \mathrm{~A}}-\mathrm{Rs}$ are involved in the behavioral and electrophysiological effects of hallucinogenic drugs and in the regulation of sensorimotor gating (Gonzalez-Maeso et al., 2007; Krebs-Thomson et al., 2006; van den Buuse et al., 2011; Vollenweider et al., 1998; Winter et al., 2000). Previous studies showed that 5-MeO-DMT and other serotonergic hallucinogens inhibited rat dorsal raphe cell firing (Demontigny and Aghajanian, 1977) and reduced 5-HT turnover (Fuxe et al., 1972) and release (Riga et al., 2016).

Brain electrical activity displays simultaneous rhythms of different frequency whose coalescence and synchronization is mainly dependent on the interplay of the cortico-thalamic systems (Steriade, 2006). Specifically, cortical oscillations have a key role in brain function due to their involvement in 
input selection, synaptic plasticity, memory consolidation and overall information processing (Buzsaki and Draguhn, 2004). Alterations in oscillatory activity have been associated with psychiatric disorders such as schizophrenia (Uhlhaas and Singer, 2010) and depression (Clark et al., 2016) and have been found in healthy volunteers after the consumption of psychotomimetic agents (AcostaUrquidi, 2015; Kometer et al., 2015; Muthukumaraswamy et al., 2013; Riba et al., 2002). Moreover, alterations in cortical oscillatory activity have been reported in neurodevelopmental and pharmacological models of schizophrenia (Celada et al., 2008; Goto and Grace, 2006; Kargieman et al., 2007; Riga et al., 2016; Riga et al., 2014). Additionally, antidepressant treatments modulate cortical oscillatory activity (Leuchter et al., 2017).

Given the role of 5-HT in modulating oscillatory activity at several frequency bands (Puig and Gener, 2015), changes on 5-HT concentration after 5-MeO-DMT, together with its action on 5-HT $\mathrm{T}_{1 \mathrm{~A}} \mathrm{R}$ and $5-\mathrm{HT}_{2 \mathrm{~A}}-\mathrm{R}$ are expected to affect the synchronization of neuronal networks. Hence, we previously reported that 5-MeO-DMT altered (51\% excited, $35 \%$ inhibited) the frequency and pattern of discharge of layer $\mathrm{V}$ pyramidal neurons in the medial prefrontal cortex (MPFC) and reduced the power of low frequency oscillations in anesthetized rats (Riga et al., 2014). Additionally, 5-MeODMT reduced low frequency oscillations in MPFC and primary sensory cortices (S1, Au1 and V1) of wild-type (WT), and -interestingly- in mPFC and V1 of 5- $\mathrm{HT}_{2 \mathrm{~A}}-\mathrm{R}$ knockout (KO2A) mice, thus pointing to the involvement of 5-HT $\mathrm{HA}_{1 \mathrm{~A}} \mathrm{R}$ in 5-MeO-DMT effects (Riga et al., 2016). This view is also supported by behavioral studies in mice lacking $5-\mathrm{HT}_{1 \mathrm{~A}}-\mathrm{R}$ and in rats treated with the $5-\mathrm{HT}_{1 \mathrm{~A}}-\mathrm{R}$ antagonist WAY100635 (Krebs-Thomson et al., 2006; Tricklebank et al., 1985; van den Buuse et al., 2011; Winter et al., 2000).

Recently, clinical studies reported the efficacy of psilocybin for treatment-resistant depression, an effect perhaps related to activity changes of thalamic and PFC areas, as reported in fMRI studies (Carhart-Harris et al., 2012) and to the modulation in the oscillatory activity observed on EEG (Kometer et al., 2015). Similar actions have been reported after ketamine administration (Vollenweider and Kometer, 2010), a non-competitive NMDA-R antagonist with proven efficacy in treatment-resistant depression (Zarate et al., 2006).

At the preclinical level, previous studies in anesthetized rodents showed that psychotropic agents with different mechanism of action, such as the non-competitive NMDA receptor antagonist phencyclidine (PCP) (Kargieman et al., 2012; Kargieman et al., 2007), the preferential $5-\mathrm{HT}_{2 \mathrm{~A}}-\mathrm{R}$ agonist DOI (Celada et al., 2008) and the non-selective 5-HT $1 \mathrm{~A} / 2 \mathrm{~A}-\mathrm{R}$ agonist 5-MeO-DMT (Riga et al., 
2016; Riga et al., 2014), markedly altered the activity of prefrontal cortex (PFC), disrupting pyramidal neuron discharge and reducing low frequency cortical oscillations. Classical and atypical antipsychotic drugs reversed these alterations (Llado-Pelfort et al., 2016; Riga et al., 2016). In the present study, we investigated the actions of 5-MeO-DMT on cortico-thalamic oscillatory activity in freely moving WT and the potential involvement of $5-\mathrm{HT}_{1 \mathrm{~A}}-\mathrm{R}$ using genetic (KO2A mice) and pharmacological manipulations. The main objectives of the study were to gain further insight into the neurobiological basis of hallucinations and to identify new targets for its treatment. Additionally, given the potential use of serotonergic hallucinogens to treat mood and anxiety disorders, we aimed to increase the knowledge of the actions of 5-MeO-DMT in key brain areas related to these psychiatric disorders. 


\section{Material and methods}

\subsection{Animals}

We used 9-16 week-old male homozygous 5- $\mathrm{HT}_{2 \mathrm{~A}}-\mathrm{R}$ knockout mice (referred as $\mathrm{KO} 2 \mathrm{~A}$ ) and wild-type mice (WT) of the same genetic background (C57/BL6). Generation of KO2A strain has been reported elsewhere (Fiorica-Howells et al., 2002). Animal care followed the European Union regulations (directive 2010/63 of 22/09/2010) and was approved by the Institutional Animal Care and Use Committee.

\subsection{Drugs and treatments}

5-Methoxy-N,N-dimethyltryptamine (5-MeO-DMT), risperidone (RIS) and WAY-100635 (WAY) maleate were from Sigma/RBI (Natick, MA). All drugs were dissolved in saline (vehicle) and injected subcutaneously (s.c.) in the same volume $(10 \mathrm{ml} / \mathrm{kg})$. The doses used are expressed as free bases and were chosen according to the literature (Riga et al., 2016; van den Buuse et al., 2011) or from pilot experiments.

On the recording day, WT and KO2A mice were treated, with a time interval between injections of 30 minutes, with: 1$)$ saline + saline $(10 \mathrm{ml} / \mathrm{kg}$ each injection) (SAL + SAL) ( $\mathrm{n=13}$ and 7 for WT and KO2A mice, respectively); 2) saline + 5-MeO-DMT (5 mg/kg) (SAL + 5-MeO-DMT) ( $\mathrm{n}=10$ and 9 for WT and KO2A mice, respectively). In order to study the potential prevention of 5-MeO-DMT-induced effects on cortico-thalamic activity, WT mice were also injected with 3 ) risperidone (5-HT $2 A-R / D_{2}-R$ antagonist) $(1 \mathrm{mg} / \mathrm{kg})+$ 5-MeO-DMT (RIS + 5-MeO-DMT) $(\mathrm{n}=10)$ and 4) risperidone + saline (RIS + $\mathrm{SAL})(\mathrm{n}=8)$ while KO2A mice were also administrated with 5) WAY-100635 (5-HT $1 \mathrm{~A}-\mathrm{R}$ antagonist) (0.5 $\mathrm{mg} / \mathrm{kg})+$ 5-MeO-DMT (WAY + 5-MeO-DMT) $(\mathrm{n}=8)$ and 6) WAY-100635 + saline (WAY + SAL) $(n=8)$. Each mouse was treated randomly once with each pharmacological treatment as shown in Supplementary Fig. S1A.

\subsection{Electrophysiology: local field potential (LFP) recordings in freely-moving mice}


A total of 24 mice (14 WT and $10 \mathrm{KO} 2 \mathrm{~A}$ ) were implanted with Plastics One electrodes (Virgina, USA) under isoflurane anesthesia (induction: 2.5\%; maintenance: 1.5\%). Animals were pretreated (30 minutes before anesthesia inhalation) with an analgesic (Buprenorfine: $0.05 \mathrm{mg} / \mathrm{kg}$ s.c.). Stereotaxic coordinates were taken from bregma and brain surface $(\mathrm{mm})$ according to the mouse brain atlas: (Franklin and Paxinos, 2008) medial prefrontal cortex (mPFC) AP + 2.2, L-0.3, DV-2.0; primary visual cortex (V1) AP-3.6, L-2.5, DV-0.5. Some mice (9 WT and $9 \mathrm{KO} 2 \mathrm{~A}$ ) were also implanted in mediodorsal nucleus of the thalamus (MD) AP-1.2, L-0.4, DV-3. A ground screw and three stabilizer screws were also implanted. The implant was fixed with dental cement. Buprenorfine $(0.05 \mathrm{mg} / \mathrm{kg} \mathrm{s.c.})$ and a prophylactic antibiotic (Enrofloxacina $7.5 \mathrm{mg} / \mathrm{kg}$ s.c.) were given during 2-3 consecutive days after surgery.

Local field potential (LFP) recordings were performed in a $40 \times 40 \mathrm{~cm}$ open field using a digital Lynx system and Cheetah software (Neuralynx, Montana, USA). The signal was obtained at $3.2 \mathrm{kHz}$ sampling rate and filtered between 0.1 and $100 \mathrm{~Hz}$. All recordings were posteriorly downsampled 10 times before analysis. Recordings were made once a week starting one week after surgery. All mice were habituated to the experimental setting for 4-5 days before recordings. On the recording day, first and second drugs (or vehicle) were injected 30 min apart, and recordings were performed for $30 \mathrm{~min}$ after each injection. The time to assess 5-MeO-DMT effect was chosen according to pharmacokinetic and behavioral studies (Halberstadt et al., 2011; Shen et al., 2011; van den Buuse et al., 2011). There was a wash-out period of at least one week after each experiment (Supplementary Fig. S1A-B).

At the end of recordings, mice were euthanatized by an anesthetic overdose. Histological localization of electrodes was performed by passage of current (intensity: $0.15 \mathrm{~mA}$; duration: $10 \mathrm{~s}$ ). Brain sections were stained according to standard procedures, to verify recordings sites (Supplementary Fig. S1C).

\subsection{Data and statistical analysis}

Data were imported to MATLAB environment (MathWorks, MA, USA) for off-line power and coherence wavelet analysis, using built-in and self-developed routines. The frequency bands analysed were delta $(0.2-4 \mathrm{~Hz})$, theta $(4-10 \mathrm{~Hz})$, beta $(10-30 \mathrm{~Hz})$ and gamma $(30-80 \mathrm{~Hz})$. Data were averaged in 5-min periods. Injection periods (5 min after $1^{\text {st }}$ and $2^{\text {nd }}$ drug administrations) were excluded from analysis. Data were expressed as areas under curve (AUCs) of every treatment period 
(5-30 minutes post- $1^{\text {st }}$ and $2^{\text {nd }}$ drug administration). Comparisons were made by determining the two AUCs for each mouse. In order to compare pharmacological treatments, normalized AUCS (POWER values (\%) and COHERENCE values (\%)) were used. In basal value and antagonist (risperidone and WAY-100635) comparisons, we used AUCs of raw data.

Data are shown as mean \pm SEM. Statistical analysis was performed using Student's t- tests (for dependent or independent samples) or three- or two-way ANOVAs (genotype, area and band or treatment and time as factors) followed by post-hoc analysis using Duncan's test, as appropriate. Statistical significance was set at the $95 \%$ confidence level (two tailed). 


\section{Results}

\subsection{Effect of saline on oscillatory activity in cortico-thalamic networks in WT mice.}

Before assessing 5-MeO-DMT effect on power spectra and coherences, we evaluated the effect of a saline injection on these variables in order to subtract them from the effect of 5-MeO-DMT, thus avoiding the contribution of mouse manipulation, saline injection and environmental adaptation. WT mice showed a small, yet significant, decrease in gamma power in the 30-min period post-saline injection in all examined areas. Moreover, they showed a slight increase in delta, theta and beta powers in V1 and MD in the same period. Effects were small, ranging between $93 \pm 1$ and $115 \pm 4$ $\%$ of pre- saline administration values (Supplementary Table S1A).

On the other hand, saline injection did not affect coherences between all examined areas in WT mice (Supplementary Table S1B).

3.2 Effect of 5-MeO-DMT on oscillatory activity in cortico-thalamic networks in WT mice.

In WT mice, 5-MeO-DMT increased theta and gamma bands in MPFC and delta power in V1. Moreover, in MD, 5-MeO-DMT decreased marginally beta power. 5-MeO-DMT effect was more marked in cortical than in thalamic areas. All values and statistical significances are shown in Table 1A. Fig. 1 shows the time course of the effects of SAL + SAL and SAL + 5-MeO-DMT for all analyzed bands and areas.

On the other hand, in WT mice, 5-MeO-DMT increased mPFC-V1 coherence in the beta band and mPFC-MD coherence in theta and beta bands. Finally, 5-MeO-DMT increased V1-MD coherence in the beta band (Table 1B). Fig. 2 shows the time course of the effect of SAL + SAL and SAL + 5-MeODMT for all analyzed coherences.

\subsection{Effects of risperidone on oscillatory activity in cortico-thalamic networks in WT mice.}

Before studying the potential prevention of 5-MeO-DMT effects by the atypical antipsychotic risperidone (RIS, 5- $\mathrm{HT}_{2 \mathrm{~A}}-\mathrm{R}$ and $\mathrm{D}_{2}-\mathrm{R}$ antagonist), we examined the actions of the antagonist alone. To this end, we compared the effect of RIS with saline administration. For each animal, only values 
corresponding to the first saline and antagonist administrations (Supplementary Figure $1 \mathrm{~A}$ ) were used for the comparison.

RIS administration decreased theta power in the MPFC of WT mice. On the other hand, RIS by itself did not alter coherence in any band examined (Supplementary Table S2).

3.4 Prevention by risperidone of 5-MeO-DMT effect on oscillatory activity in cortico-thalamic networks in WT mice.

Given its high affinity for $5-\mathrm{HT}_{2 \mathrm{~A}}-\mathrm{R}$, we pretreated WT mice with risperidone to assess the involvement of $5-\mathrm{HT}_{2 \mathrm{~A}}-\mathrm{R}$ in $5-\mathrm{MeO}-\mathrm{DMT}$ regionally-selective effects. We focused only in the prevention of the significant effects shown in Fig. 1-2 and Table 1.

In WT mice, pretreatment with risperidone only prevented 5-MeO-DMT effect in mPFC theta band but not in MPFC gamma band neither in V1 delta and MD beta bands. Moreover, risperidone prevented only 5-MeO-DMT actions in MPFC-MD coherence (theta and beta bands) (Fig. 3). Statistical analysis is shown in Supplementary Table S3A.

\subsection{Oscillatory activity in cortico-thalamic networks: comparison between WT and KO2A mice}

Since pretreatment with risperidone failed to avoid all 5-MeO-DMT effects in WT mice and given the high affinity for $5-\mathrm{HT}_{1 \mathrm{~A}}-\mathrm{R}$ showed by $5-\mathrm{MeO}-\mathrm{DMT}$, we decided to study the involvement of this receptor using genetic (KO2A mice) and $5-\mathrm{HT}_{1 \mathrm{~A}}-\mathrm{R}$ pharmacological manipulations to better understand the mechanism of action of 5-MeO-DMT.

Comparisons of basal power spectra between genotypes are shown in Supplementary Table S4. Delta band power did not differ between genotypes in MPFC and V1. Likewise, there were no differences between genotypes in theta, beta and gamma powers in mPFC whereas significant differences were found in theta, beta and gamma bands in V1. Similarly to MPFC, there were no differences between genotypes in the power of all analyzed bands in MD.

On the other hand, the mPFC-V1 coherence differed between genotypes in delta band but not in other bands. In other analyzed coherences (mPFC-MD and V1-MD), no significant differences were found for all examined bands.

3.6 Effect of saline on oscillatory actvity in cortico-thalamic networks in KO2A mice. 
As observed in WT mice, KO2A mice showed a small decrease in gamma power in the 30-min period post-saline injection in all examined areas and a slight increase in delta, theta and beta powers in $\mathrm{V} 1$ and MD in the same period. Effects were small, ranging between $93 \pm 3$ and $121 \pm 4 \%$ of presaline administration values (Supplementary Table S1A).

Regarding interregional coherence of oscillations, only KO2A mice showed a slight increase in mPFCMD coherence in theta and in MPFC-V1 and V1-MD coherences in beta. Effects were small ranging between $101.8 \pm 0.4$ and $105.0 \pm 1.2 \%$ of pre-saline administration values (Supplementary Table S1B).

3.7 Effect of 5-MeO-DMT on oscillatory activity in cortico-thalamic networks in KO2A mice.

In mPFC, 5-MeO-DMT increased the power of all examined bands in KO2A mice. Moreover, in V1, 5-MeO-DMT increased delta, theta and beta bands. Finally, 5-MeO-DMT increased delta power in MD. 5-MeO-DMT effect was more marked in cortical than in thalamic areas. All values and statistical significances are shown in Table 1. Fig. 4 shows the time course of the effects of SAL + SAL and SAL +5-MeO-DMT for all analyzed bands and areas.

On the other hand, 5-MeO-DMT increased the mPFC-V1 coherence in delta, theta and beta bands of KO2A mice. 5-MeO-DMT increased mPFC-MD coherence in delta, theta and beta bands of KO2A mice. Finally, 5-MeO-DMT increased V1-MD coherence in delta (marginally) and beta bands of KO2A mice. All data and statistical significances are shown in Table 1. Fig. 5 shows the time course of the effect of SAL + SAL and SAL + 5-MeO-DMT for all analyzed inter-regional coherences.

\subsection{Effect of 5-MeO-DMT on oscillatory activity in cortico-thalamic networks: comparison between genotypes, areas and band frequencies}

We carried out a further statistical analysis using three-way ANOVAs for power and coherence data in order to assess the effect of genotype, area and band, as well as their interactions. In terms of power, the most affected areas by 5-MeO-DMT were mPFC and V1. The more marked effect was an elevation of delta power in V1 of KO2A mice (258 $\pm 44 \%$ of pre-drug administration values) suggesting a relevant action of 5-MeO-DMT on 5- $\mathrm{HT}_{1 \mathrm{~A}}-\mathrm{R}$ in $\mathrm{V} 1$ delta band. Fig. 6 shows representative examples of the effects of 5-MeO-DMT on delta, theta, beta and gamma in MPFC (A and $A$ ), V1 ( $C$ and $D$ ) and MD (E and F) powers in WT and KO2A mice. Three-way ANOVA is shown in Supplementary Table S3B. Post-hoc analysis revealed significant differences between 5-MeO-DMT 
effects in WT and KO2A mice in V1, between 5-MeO-DMT effect on delta oscillation in KO2A in V1 and other areas and between 5-MeO-DMT effects in V1 delta in KO2A compared to other bands in this area (Fig. 6G).

5-MeO-DMT markedly affected the coherences between MPFC and MD. The more marked effect was observed in the beta band of KO2A mice (122 $\pm 2 \%$ of pre-drug administration values), indicating that 5-MeO-DMT increased mPFC-MD coherence via activation of $5-\mathrm{HT}_{1 \mathrm{~A}}-\mathrm{R}$. Three-way ANOVA values are shown in Supplementary Table S3B. Significant post-hoc differences between 5MeO-DMT effects in mPFC-MD and mPFC-V1/V1-MD coherences at different bands were found (Fig. $6 \mathrm{H})$.

\subsection{Effects of WAY-100635 on oscillatory activity in cortico-thalamic networks in KO2A mice.}

As assessed for RIS in WT mice, here we examined the actions of the $5-\mathrm{HT}_{1 \mathrm{~A}}-\mathrm{R}$ antagonist WAY100635 (WAY) alone. To this end, we compared the effect of WAY with saline administration. For each animal, only values corresponding to the first saline and antagonist administrations (Supplementary Fig. 1A) were used for the comparison.

WAY increased beta power in the MD of KO2A mice but it did not alter coherence in any band and genotype examined (Supplementary Table S2).

\subsection{Prevention by WAY-100635 of 5-MeO-DMT effect on oscillatory activity in cortico-} thalamic networks in KO2A mice.

5-MeO-DMT induced differential effects on oscillatory activity in WT and KO2A mice. Moreover, 5$\mathrm{HT}_{2 \mathrm{~A}}-\mathrm{R}$ blockade induced by risperidone failed to prevent all 5-MeO-DMT effects in WT mice. Here, we decided to confirm the dependence on $5-\mathrm{HT}_{1 \mathrm{~A}}-\mathrm{R}$ of 5-MeO-DMT effects found in KO2A mice. To this aim, we pretreated KO2A mice with WAY-100635 in order to prevent 5-MeO-DMT effects. We focused only in the prevention of the significant effects of 5-MeO-DMT on oscillatory activity shown in Fig. 4-5 and Table 1.

In KO2A, WAY-100635 prevented all effects on the different band power induced by 5-MeO-DMT, regardless of the area or band examined (Fig. 7). Similarly to the effects on power, pretreatment with WAY-100635 avoided 5-MeO-DMT effects in all interegion coherences examined, except in delta V1-MD coherence (Fig. 7). Statistical analysis is shown in Supplementary Table S3C. 


\section{Discussion}

The present results indicate that the hallucinatory effect of 5-MeO-DMT is associated to a simultaneous alteration of the oscillatory activity in primary visual cortex (V1) and in corticothalamic (mPFC-MD) circuits. Interestingly, the effects of 5-MeO-DMT on the different intraregional power bands and interregional band coherences examined were more marked in KO2A mice, indicating that $5-\mathrm{HT}_{1 \mathrm{~A}}-\mathrm{R}$ activation plays a relevant role in the psychotropic action of 5-MeO-DMT. The greater effect size on oscillatory activity in KO2A mice suggests that the simultaneous activation of $5-\mathrm{HT}_{2 \mathrm{~A}}-\mathrm{R}$ (absent in $\mathrm{KO} 2 \mathrm{~A}$ mice) attenuates $5-\mathrm{HT}_{1 \mathrm{~A}}-\mathrm{R}$-mediated effects, an effect possibly related to the high cellular co-expression on both receptors in PFC and their opposite role on pyramidal cell function (Amargos-Bosch et al., 2004; Araneda and Andrade, 1991; Puig et al., 2005) (see below for extended discussion). The involvement of $5-\mathrm{HT}_{1 \mathrm{~A}}-\mathrm{R}$ in the effect of $5-\mathrm{MeO}-\mathrm{DMT}$ adds to previous observations in visual cortex of anesthetized mice (Riga et al., 2016) and suggests the therapeutic potential of $5-\mathrm{HT}_{1 \mathrm{~A}}-\mathrm{R}$ antagonists in the treatment of visual and perhaps other forms of hallucinations, which lack appropriate therapy. Moreover, 5-MeO-DMT-induced changes on oscillatory activity and synchronization in PFC and thalamus, two keys areas implicated in major depression.

Serotonin hallucinogens alter cortical oscillatory activity, affecting frequency bands in a differential manner (Acosta-Urquidi, 2015; Muthukumaraswamy et al., 2013; Riba et al., 2002). 5-MeO-DMT markedly increased theta and gamma bands in MPFC, as also observed in the frontal area of individuals inhaling 5-MeO-DMT (Acosta-Urquidi, 2015). Interestingly, 5-MeO-DMT increased the power of some bands (mPFC-delta; mPFC-beta, V1-theta or V1-beta) in KO2A but not in WT mice. These results suggest that 5-MeO-DMT has opposite effects when acting on 5- $\mathrm{HT}_{1 \mathrm{~A}}-\mathrm{R}$ (increase, as observed in $\mathrm{KO} 2 \mathrm{~A}$ mice) or $5-\mathrm{HT}_{2 \mathrm{~A}}-\mathrm{R}$ (decrease). Hence, the effect on WT mice reflects the balance between these opposite actions. Accordingly, 5- $\mathrm{HT}_{1 \mathrm{~A}}-\mathrm{R}$ agonists increase (Murck et al., 2001; Seifritz et al., 1996; Tissier et al., 1993), and the preferential 5- $\mathrm{HT}_{2 \mathrm{~A}}-\mathrm{R}$ agonists $\mathrm{DMT}$ and psilocybin decrease delta power (Muthukumaraswamy et al., 2013; Riba et al., 2002).

In anesthetized KO2A mice, 5-MeO-DMT decreases delta power in MPFC, an effect dependent on 5$\mathrm{HT}_{1 \mathrm{~A}}-\mathrm{R}$ activation (Riga et al., 2016). In awake KO2A mice, 5-MeO-DMT increased delta power, an 
effect also dependent on $5-\mathrm{HT}_{1 \mathrm{~A}}-\mathrm{R}$ activation, as observed by its prevention by WAY-100635. The opposite effect of 5-MeO-DMT on delta band power in anesthetized vs awaken KO2A mice may be due to a different cortical excitation/inhibition balance. As $5-\mathrm{HT}_{1 \mathrm{~A}} \mathrm{R}$ is expressed in GABAergic and pyramidal neurons (Santana et al., 2004), our observations in KO2A mice may reflect a preferential action of 5-MeO-DMT on 5- $\mathrm{HT}_{1 \mathrm{~A}}-\mathrm{R}$ in GABAergic interneurons (anesthetized) or in pyramidal neurons (awake). Supporting this, low doses of the $5-\mathrm{HT}_{1 \mathrm{~A}}-\mathrm{R}$ agonist 8-OH-DPAT decreased delta power (unpublished results) and increased pyramidal neuron discharge in anesthetized rats, through a preferential action on 5- $\mathrm{HT}_{1 \mathrm{~A}}-\mathrm{R}$ located on GABAergic interneurons (Llado-Pelfort et al., 2012). Additionally, WAY-100635 had no effect on delta activity in awake mice (Supplementary Table S5) whereas it increased delta activity in anesthetized mice (Riga et al., 2016).

In humans, patients with schizophrenia show alterations in cortical gamma oscillations when performing cognitive tasks (reductions) (Cho et al., 2006), or during resting state (increases) (Kikuchi et al., 2011) when compared with control subjects. Likewise, cortical gamma power increases in healthy individuals taking ketamine (Hong et al., 2010) or 5-MeO-DMT (Acosta-Urquidi, 2015). In agreement with these observations, here we found an increase in mPFC-gamma band power after 5-MeO-DMT. Increases in gamma power have been also reported in freely-moving animals after NMDA-R antagonist administration (Goonawardena et al., 2016; Wood et al., 2012). On the contrary, the 5-HT $\mathrm{H}_{2 \mathrm{~A} / 2 \mathrm{C}}-\mathrm{R}$ agonist $\mathrm{DOI}$ decreases gamma power in freely-moving rats (Wood et al., 2012). The different effect evoked by these two serotonergic hallucinogens (DOI and 5-MeO-DMT) may be due to the preferential action of 5-MeO-DMT on 5- $\mathrm{HT}_{1 \mathrm{~A}}-\mathrm{R}$ (McKenna et al., 1990), given the similar effect of this drug on MPFC-gamma band in WT and KO2A mice. Interestingly WAY-100635, but not risperidone, prevented 5-MeO-DMT effect on MPFC-gamma band, supporting the involvement of $5-\mathrm{HT}_{1 \mathrm{~A}}-\mathrm{R}$ in this effect (whereas that of DOI depends on $5-\mathrm{HT}_{2 \mathrm{~A}}-\mathrm{R}$ ). Consistently, the preferential 5- $\mathrm{HT}_{1 \mathrm{~A}}-\mathrm{R}$ agonist 5-MeO-DMT increases (Acosta-Urquidi, 2015) whereas the preferential 5- $\mathrm{HT}_{2 \mathrm{~A}}-\mathrm{R}$ agonist psilocybin decreases (Muthukumaraswamy et al., 2013) gamma power in humans.

Focusing on the activity of the Visual Cortex, visual hallucinations are associated with increases on basal activity in the visual cortex (Ffytche et al., 1998) and aberrant activity within visual thalamocortical networks (Carter and Ffytche, 2015). Patients with paranoid schizophrenia show alterations in the visual processing (Seymour et al., 2013). Here we report that 5-MeO-DMT altered oscillatory activity on V1. Interestingly, individuals taking Ayahuasca (an Amazonian beverage containing 
dimethyltryptamines) show an altered oscillatory activity in the occipital cortex (visual cortex in humans) in parallel with alterations in visual perception (de Araujo et al., 2012; Riba et al., 2002; Valle et al., 2016). Other psychedelics also alter visual information processing (Carter et al., 2005; de Araujo et al., 2012; Kometer et al., 2011; Kometer et al., 2013; Riba et al., 2002). Hence, in humans, 5-MeO-DMT-induced hallucinations have been related to increases on parietal cortex gamma band (Acosta-Urquidi, 2015).

5-HT ${ }_{2 A}-\mathrm{R}$ and 5- $\mathrm{HT}_{1 \mathrm{~A}}-\mathrm{R}$ are expressed in the visual cortex (Dyck and Cynader, 1993; Gerstl et al., 2008; Moreau et al., 2010; Saulin et al., 2012; Watakabe et al., 2009). 5-HT acting on these receptors may modulate the excitatory/inhibitory balance, as observed in MPFC (Amargos-Bosch et al., 2004). Specifically, $5-\mathrm{HT}_{2 \mathrm{~A}}-\mathrm{R}$ mediated distinct, and layer dependent, modulation of layer III and VI inputs to layer $V$ pyramidal neurons, according with the specific expression of these receptors on pyramidal neurons and interneurons (Moreau et al., 2010). 5- $\mathrm{HT}_{2 \mathrm{~A}} \mathrm{R}$ plays a fundamental role in the pathogenesis of visual hallucinations (Moreau et al., 2010) and altered expression has been reported in patients with visual hallucinations and untreated schizophrenic subjects (Ballanger et al., 2010; Gonzalez-Maeso et al., 2008).

KO2A mice showed an altered V1 baseline oscillatory activity in theta, beta and gamma bands power. Additionally, KO2A mice showed a decrease in theta coherence between mPFC and V1. These alterations may be related to the role of $5-\mathrm{HT}_{2 \mathrm{~A}}-\mathrm{R}$ on visual processing (Kometer et al., 2011; Moreau et al., 2010).

5-MeO-DMT alters low band oscillatory activity of visual and prefrontal cortices more markedly in $\mathrm{KO} 2 \mathrm{~A}$ than in WT mice, suggesting a preferential action on $5-\mathrm{HT}_{1 \mathrm{~A}}-\mathrm{R}$ and/or opposite effects of 5MeO-DMT acting on $5-\mathrm{HT}_{2 \mathrm{~A}}-\mathrm{R}$ (decrease power) and $5-\mathrm{HT}_{1 \mathrm{~A}}-\mathrm{R}$ (increase power). Consistent with this last hypothesis, and as occurs in $\mathrm{MPFC}$, we found a more marked increase in V1-delta band in KO2A mice. Interestingly, DMT decreases delta and theta bands over the temporo-parieto occipital junction, supporting its preferential action on 5- $\mathrm{HT}_{2 \mathrm{~A}}-\mathrm{R}$ (Riba et al., 2004).

Serotonin hallucinogens decrease al pha oscillations and increase cerebral blood flow (CBF) on visual areas (Carhart-Harris et al., 2016b; de Araujo et al., 2012; Riba et al., 2004). In humans, alpha (8-13 $\mathrm{Hz}$ ) rhythm dominates EEG in sensory brain areas during relaxed wakefulness and is strongly influenced by thalamic activity. In rats, the equivalent predominant band oscillates approximately at 5-12 Hz (Hughes and Crunelli, 2005). Despite we have not specifically analyzed the alpha band, 
our analyses in V1 found no significant change on theta $(4-10 \mathrm{~Hz})$ or beta $(10-30 \mathrm{~Hz})$ bands in WT whereas power of both bands increased in KO2A mice after 5-MeO-DMT suggesting again that 5MeO-DMT induces opposite effects on these bands acting on $5-\mathrm{HT}_{2 \mathrm{~A}^{-}} \mathrm{R}$ (decrease power) or $5-\mathrm{HT}_{1 \mathrm{~A}^{-}}$ R (increase power). Moreover, all alterations were prevented by WAY-100635, supporting the involvement of $5-\mathrm{HT}_{1 \mathrm{~A}}-\mathrm{R}$.

The effects of 5-MeO-DMT were more marked in $\mathrm{V} 1$ and mPFC than in MD thalamus, consistent with the high density of $5-\mathrm{HT}_{1 \mathrm{~A}}-\mathrm{R}$ and $5-\mathrm{HT}_{2 \mathrm{~A}}-\mathrm{R}$ in these cortical areas and their absence in thalamic nuclei (Pompeiano et al., 1992, 1994; Santana et al., 2004). Hence, the increase in delta band power induced by $5-\mathrm{MeO}-\mathrm{DMT}$ in MD cannot be explained by a local effect and suggests the involvement of delta rhythms in organizing thalamo-cortical activity (Steriade, 2006), in agreement with the dense reciprocal connectivity between PFC and MD (Gabbott et al., 2005; Kuroda et al., 1998). This view is also supported by the increased coherence between mPFC and MD after 5-MeO-DMT administration. However, given the absence of a direct connectivity between V1 and MD, the increased V1-MD coherence may be explained by the direct reciprocal V1-PFC and MD-PFC connectivity. Not surprisingly, 5-MeO-DMT did not alter the power of higher frequency bands in $\mathrm{MD}$, which are more dependent on local cellular and synaptic activity than delta oscillations.

The role of serotonergic neurotransmission on the synchrony between brain areas is poorly known. Coherence gives information about inter-area synchronization, measuring interactions between two neuronal populations and is considered a very sensitive measure of high cognitive processes (Rappelsberger and Petsche, 1988; Sarnthein et al., 1998). 5-MeO-DMT increased coherence in beta band between all areas examined. Similarly, in humans, 5-MeO-DMT intake increases perception and coherence between cortical areas (Acosta-Urquidi, 2015). Comparable increases in beta coherence have been reported after ketamine (Palenicek et al., 2011). As discussed above, coherence between MPFC and MD thalamus was the most affected coherence, probably due to the dense and reciprocal cortico-thalamic connectivity between these two areas (Gabbott et al., 2005; Groenewegen and Uylings, 2000).

The changes in coherence evoked by 5-MeO-DMT in WT and KO2A mice indicate that 5- $\mathrm{HT}_{1 \mathrm{~A}}-\mathrm{R}$ and $5-\mathrm{HT}_{2 \mathrm{~A}}-\mathrm{R}$ are involved in inter-area synchrony. The different prevention of 5-MeO-DMT-induced increase in coherence between areas by WAY-100635 and risperidone supports that both receptors play a differential role in regulating the synchrony between the 3 areas examined. Hence, in WT, the $5-\mathrm{HT}_{2 \mathrm{~A}}-\mathrm{R}$ blockade induced by risperidone prevented only 5-MeO-DMT effects in mPFC theta 
band and in PFC-MD theta and beta coherences, without excluding a role for the blockade of DA D2 receptors in the risperidone preventing action. Interestingly, pretreatment with WAY100635 avoided all 5-MeO-DMT effects on power spectra and coherences except in delta V1-MD coherence. Non-competitive NMDA-R antagonist such as ketamine (Monteggia and Zarate, 2015; Zarate et al., 2006) and serotonergic hallucinogens such as psilocybin (Carhart-Harris et al., 2016a) show clinical efficacy in depressed patients resistant to other forms of treatment (Baumeister et al., 2014; Vollenweider and Kometer, 2010). Likewise, several studies have reported antidepressant efficacy of Ayahuasca, containing dimethyltryptamines in varying proportions (Sanches et al., 2016).

Psilocybin decreases blood flow and BOLD signals in the anterior and posterior cingulate cortex, key areas of the default mode network (DMN), a set of brain regions that are active during awake resting state (Muthukumaraswamy et al., 2013; Raichle et al., 2001), and in the thalamus (Carhart-Harris et al., 2012). Similarly, ketamine decreases the functional connectivity between the DMN and various cingulate and prefrontal areas in healthy individuals (Scheidegger et al., 2012). The activity of this network is related to introspection and mind wandering (Sheline et al., 2009; Sood and Jones, 2013) and some of these areas have been implicated in major depression (Mayberg et al., 2005). Likewise, psychedelics such as Ayahuasca decrease the activity of several DMN areas (Palhano-Fontes et al., 2015) and change the coupling of brain oscillations, reducing the influence of frontal to posterior areas (Alonso et al., 2015).

Antidepressant treatment (Leuchter et al., 2017) and meditation (Cahn and Polich, 2006) increase frontal theta activity. In this regard, the increase in PFC theta activity evoked by 5-MeO-DMT may be related to a potential antidepressant activity. Also, optogenetic theta rhythm stimulation of the antero-cingulate cortex reduced anxiety-related behavior in mice (Weible et al., 2017). Finally, 5MeO-DMT increased PFC-MD coherence. Interestingly, depressive patients show a decrease in the connectivity between the thalamus and the antero-cingulate cortex (Anand et al., 2005a) whereas antidepressant treatment and LSD increase cortico-thalamic connectivity (Anand et al., 2005b; Tagliazucchi et al., 2016).

\section{Conclusions}


The present results indicate that 5-MeO-DMT simultaneously alters population activity in PFC-MD circuits and in V1 (primary visual cortex), effects likely related to the visual hallucinations and introspection induced by this agent. In terms of power, the greater effect size was found in V1 (delta band) whereas the most affected synchrony was that between MPFC and MD. The more marked effects in KO2A mice, as well as their prevention by WAY-100635 support a preferential action of 5MeO-DMT on 5- $\mathrm{HT}_{1 \mathrm{~A}}$ receptors. This suggests the potential usefulness of $5-\mathrm{HT}_{1 \mathrm{~A}}$ antagonists to treat visual, and perhaps, other forms of hallucinations. Finally, the increase in PFC-theta band power and mPFC-MD coherence may be related to its potential antidepressant action. Overall, the present study contributes to the elucidation of the mechanism of action of psychedelic agents and the brain circuits involved.

\section{Funding and disclosure}

This work was supported by grants from Instituto de Salud Carlos III (PI09/01245, PI12/00156 and PI16/00287(PN de I + D + I 2008-2011, ISCIII-Subdirección General de Evaluación y Fomento de la Investigación, and by grant SAF2015-68346, from the Ministry of Economy and competitiveness, cofinanced by the European Regional Development Fund. "Una manera de hacer Europa"), Centro de Investigación Biomédica en Red de Salud Mental, (CIBERSAM P82, 11INT3. Support from the Generalitat de Catalunya (2014 SGR798) is also acknowledged. MR was supported by an IDIBAPS fellowship. F.A. has received consulting and educational honoraria from Lundbeck and he and P.C. are $\mathrm{PI}$ and CoPI respectively of two grants from Lundbeck. F.A. is also member of the scientific advisory board of Neurolixis. F.A. is author of the patent WO/2011/ 131693 for the siRNA and ASO (antisense oligonucleotides) molecules. The rest of authors declare no conflict of interest.

\section{Acknowledgements}

We acknowledge Noemí Jurado and Mercedes Nuñez for skillful technical assistance. 


\section{References}

Acosta-Urquidi, J., 2015. QEEG studies of the acute effects of the visionary tryptamine DMT. Cosmos and History-the Journal of Natural and Social Philosophy 11, 115-129.

Alonso, J. F., Romero, S., Mananas, M. A., Riba, J., 2015. Serotonergic psychedelics temporarily modify information transfer in humans. Int J Neuropsychopharmacol 18.

Amargos-Bosch, M., Bortolozzi, A., Puig, M. V., Serrats, J., Adell, A., Celada, P., Toth, M., Mengod, G., Artigas, F., 2004. Co-expression and in vivo interaction of serotonin1A and serotonin2A receptors in pyramidal neurons of prefrontal cortex. Cereb Cortex 14, 281-299.

Anand, A., Li, Y., Wang, Y., Wu, J., Gao, S., Bukhari, L., Mathews, V. P., Kalnin, A., Lowe, M. J., 2005a. Activity and connectivity of brain mood regulating circuit in depression: a functional magnetic resonance study. Biol Psychiatry 57, 1079-1088.

Anand, A., Li, Y., Wang, Y., Wu, J., Gao, S., Bukhari, L., Mathews, V. P., Kalnin, A., Lowe, M. J., 2005b. Antidepressant effect on connectivity of the mood-regulating circuit: an FMRI study. Neuropsychopharmacology 30, 1334-1344.

Araneda, R., Andrade, R., 1991. 5-Hydroxytryptamine2 and 5-hydroxytryptamine 1A receptors mediate opposing responses on membrane excitability in rat association cortex. Neuroscience 40, 399-412.

Ballanger, B., Strafella, A. P., van Eimeren, T., Zurowski, M., Rusjan, P. M., Houle, S., Fox, S. H., 2010. Serotonin 2A receptors and visual hallucinations in Parkinson disease. Arch Neurol 67, 416-421.

Baumeister, D., Barnes, G., Giaroli, G., Tracy, D., 2014. Classical hallucinogens as antidepressants? A review of pharmacodynamics and putative clinical roles. Ther Adv Psychopharmacol 4, 156-169.

Buzsaki, G., Draguhn, A., 2004. Neuronal oscillations in cortical networks. Science 304, 1926-1929.

Cahn, B. R., Polich, J., 2006. Meditation states and traits: EEG, ERP, and neuroimaging studies. Psychol Bull 132, 180-211.

Carhart-Harris, R. L., Bolstridge, M., Rucker, J., Day, C. M., Erritzoe, D., Kaelen, M., Bloomfield, M., Rickard, J. A., Forbes, B., Feilding, A., Taylor, D., Pilling, S., Curran, V. H., Nutt, D. J., 2016a. Psilocybin with psychological support for treatment-resistant depression: an open-label feasibility study. Lancet Psychiatry 3, 619-627.

Carhart-Harris, R. L., Erritzoe, D., Williams, T., Stone, J. M., Reed, L. J., Colasanti, A., Tyacke, R. J., Leech, R., Malizia, A. L., Murphy, K., Hobden, P., Evans, J., Feilding, A., Wise, R. G., Nutt, D. J., 2012. Neural correlates of the psychedelic state as determined by fMRI studies with psilocybin. Proc Natl Acad Sci U S A 109, 2138-2143.

Carhart-Harris, R. L., Muthukumaraswamy, S., Roseman, L., Kaelen, M., Droog, W., Murphy, K., Tagliazucchi, E., Schenberg, E. E., Nest, T., Orban, C., Leech, R., Williams, L. T., Williams, T. M., Bolstridge, M., Sessa, B., McGonigle, J., Sereno, M. I., Nichols, D., Hellyer, P. J., Hobden, P., Evans, J., Singh, K. D., Wise, R. G., Curran, H. V., Feilding, A., Nutt, D. J., 2016b. Neural correlates of the LSD experience revealed by multimodal neuroimaging. Proc Natl Acad Sci U S A 113, 4853-4858.

Carter, O. L., Burr, D. C., Pettigrew, J. D., Wallis, G. M., Hasler, F., Vollenweider, F. X., 2005. Using psilocybin to investigate the relationship between attention, working memory, and the serotonin $1 \mathrm{~A}$ and $2 \mathrm{~A}$ receptors. J Cogn Neurosci 17, 1497-1508.

Carter, R., Ffytche, D. H., 2015. On visual hallucinations and cortical networks: a trans-diagnostic review. J Neurol 262, 1780-1790. 
Celada, P., Puig, M. V., Diaz-Mataix, L., Artigas, F., 2008. The hallucinogen DOI reduces lowfrequency oscillations in rat prefrontal cortex: reversal by antipsychotic drugs. Biol Psychiatry 64, 392-400.

Cho, R. Y., Konecky, R. O., Carter, C. S., 2006. Impairments in frontal cortical gamma synchrony and cognitive control in schizophrenia. Proc Natl Acad Sci U S A 103, 19878-19883.

Clark, D. L., Brown, E. C., Ramasubbu, R., Kiss, Z. H. T., 2016. Intrinsic Local Beta Oscillations in the Subgenual Cingulate Relate to Depressive Symptoms in Treatment-Resistant Depression. Biol Psychiatry 80, e93-e94.

de Araujo, D. B., Ribeiro, S., Cecchi, G. A., Carvalho, F. M., Sanchez, T. A., Pinto, J. P., de Martinis, B. S., Crippa, J. A., Hallak, J. E., Santos, A. C., 2012. Seeing with the eyes shut: neural basis of enhanced imagery following Ayahuasca ingestion. Hum Brain Mapp 33, 2550-2560.

Demontigny, C., Aghajanian, G. K., 1977. PREFERENTIAL ACTION OF 5-METHOXYTRYPTAMINE AND 5-METHOXYDIMETHYLTRYPTAMINE ON PRESYNAPTIC SEROTONIN RECEPTORS - COMPARATIVE IONTOPHORETIC STUDY WITH LSD AND SEROTONIN. Neuropharmacology 16, 811-818.

Dyck, R. H., Cynader, M. S., 1993. Autoradiographic localization of serotonin receptor subtypes in cat visual cortex: transient regional, laminar, and columnar distributions during postnatal development. J Neurosci 13, 4316-4338.

Ffytche, D. H., Howard, R. J., Brammer, M. J., David, A., Woodruff, P., Williams, S., 1998. The anatomy of conscious vision: an $\mathrm{fMRI}$ study of visual hallucinations. Nat Neurosci 1, 738-742.

Fiorica-Howells, E., Hen, R., Gingrich, J., Li, Z., Gershon, M. D., 2002. 5-HT(2A) receptors: location and functional analysis in intestines of wild-type and 5-HT(2A) knockout mice. Am J Physiol Gastrointest Liver Physiol 282, G877-893.

Franklin, K. B. J., Paxinos, G., 2008. The Mouse Brain in Stereotaxic Coordinates. Academic Press.

Fuxe, K., Holmstedt, B., Jonsson, G., 1972. Effects of 5-methoxy-N,N-dimethyltryptamine on central monoamine neurons. Eur J Pharmacol 19, 25-34.

Gabbott, P. L., Warner, T. A., Jays, P. R., Salway, P., Busby, S. J., 2005. Prefrontal cortex in the rat: projections to subcortical autonomic, motor, and limbic centers. J Comp Neurol 492, 145-177.

Gerstl, F., Windischberger, C., Mitterhauser, M., Wadsak, W., Holik, A., Kletter, K., Moser, E., Kasper, S., Lanzenberger, R., 2008. Multimodal imaging of human early visual cortex by combining functional and molecular measurements with fMRI and PET. Neuroimage 41, 204-211.

Geyer, M. A., Vollenweider, F. X., 2008. Serotonin research: contributions to understanding psychoses. Trends Pharmacol Sci 29, 445-453.

Gonzalez-Maeso, J., Ang, R. L., Yuen, T., Chan, P., Weisstaub, N. V., Lopez-Gimenez, J. F., Zhou, M., Okawa, Y., Callado, L. F., Milligan, G., Gingrich, J. A., Filizola, M., Meana, J. J., Sealfon, S. C., 2008. Identification of a serotonin/glutamate receptor complex implicated in psychosis. Nature 452, 9397.

Gonzalez-Maeso, J., Weisstaub, N. V., Zhou, M., Chan, P., Ivic, L., Ang, R., Lira, A., Bradley-Moore, M., Ge, Y., Zhou, Q., Sealfon, S. C., Gingrich, J. A., 2007. Hallucinogens recruit specific cortical 5$\mathrm{HT}(2 \mathrm{~A})$ receptor-mediated signaling pathways to affect behavior. Neuron 53, 439-452.

Goonawardena, A. V., Heiss, J., Glavis-Bloom, C., Trube, G., Borroni, E., Alberati, D., Wallace, T. L., 2016. Alterations in High-Frequency Neuronal Oscillations in a Cynomolgus Macaque Test of Sustained Attention Following NMDA Receptor Antagonism. Neuropsychopharmacology 41, 13191328.

Goto, Y., Grace, A. A., 2006. Alterations in medial prefrontal cortical activity and plasticity in rats with disruption of cortical development. Biol Psychiatry 60, 1259-1267.

Groenewegen, H. J., Uylings, H. B., 2000. The prefrontal cortex and the integration of sensory, limbic and autonomic information. Prog Brain Res 126, 3-28. 
Halberstadt, A. L., Koedood, L., Powell, S. B., Geyer, M. A., 2011. Differential contributions of serotonin receptors to the behavioral effects of indoleamine hallucinogens in mice. I Psychopharmacol 25, 1548-1561.

Hong, L. E., Summerfelt, A., Buchanan, R. W., O'Donnell, P., Thaker, G. K., Weiler, M. A., Lahti, A. C., 2010. Gamma and delta neural oscillations and association with clinical symptoms under subanesthetic ketamine. Neuropsychopharmacology 35, 632-640.

Hughes, S. W., Crunelli, V., 2005. Thalamic mechanisms of EEG alpha rhythms and their pathological implications. Neuroscientist 11, 357-372.

Kargieman, L., Riga, M. S., Artigas, F., Celada, P., 2012. Clozapine Reverses Phencyclidine-Induced Desynchronization of Prefrontal Cortex through a 5-HT(1A) Receptor-Dependent Mechanism. Neuropsychopharmacology 37, 723-733.

Kargieman, L., Santana, N., Mengod, G., Celada, P., Artigas, F., 2007. Antipsychotic drugs reverse the disruption in prefrontal cortex function produced by NMDA receptor blockade with phencyclidine. Proc Natl Acad Sci U S A 104, 14843-14848.

Kikuchi, M., Hashimoto, T., Nagasawa, T., Hirosawa, T., Minabe, Y., Yoshimura, M., Strik, W., Dierks, T., Koenig, T., 2011. Frontal areas contribute to reduced global coordination of resting-state gamma activities in drug-naive patients with schizophrenia. Schizophr Res 130, 187-194.

Kometer, M., Cahn, B. R., Andel, D., Carter, O. L., Vollenweider, F. X., 2011. The 5-HT2A/1A agonist psilocybin disrupts modal object completion associated with visual hallucinations. Biol Psychiatry 69, 399-406.

Kometer, M., Pokorny, T., Seifritz, E., Volleinweider, F. X., 2015. Psilocybin-induced spiritual experiences and insightfulness are associated with synchronization of neuronal oscillations. Psychopharmacology (Berl) 232, 3663-3676.

Kometer, M., Schmidt, A., Jancke, L., Vollenweider, F. X., 2013. Activation of serotonin 2A receptors underlies the psilocybin-induced effects on alpha oscillations, N170 visual-evoked potentials, and visual hallucinations. J Neurosci 33, 10544-10551.

Krebs-Thomson, K., Ruiz, E. M., Masten, V., Buell, M., Geyer, M. A., 2006. The roles of 5-HT1A and $5-\mathrm{HT} 2$ receptors in the effects of 5-MeO-DMT on locomotor activity and prepulse inhibition in rats. Psychopharmacology (Berl) 189, 319-329.

Kuroda, M., Yokofujita, J., Murakami, K., 1998. An ultrastructural study of the neural circuit between the prefrontal cortex and the mediodorsal nucleus of the thalamus. Prog Neurobiol 54, 417-458.

Leuchter, A. F., Hunter, A. M., Jain, F. A., Tartter, M., Crump, C., Cook, I. A., 2017. Escitalopram but not placebo modulates brain rhythmic oscillatory activity in the first week of treatment of Major Depressive Disorder. J Psychiatr Res 84, 174-183.

Llado-Pelfort, L., Santana, N., Ghisi, V., Artigas, F., Celada, P., 2012. 5-HT1A receptor agonists enhance pyramidal cell firing in prefrontal cortex through a preferential action on GABA interneurons. Cereb Cortex 22, 1487-1497.

Llado-Pelfort, L., Troyano-Rodriguez, E., van den Munkhof, H. E., Cervera-Ferri, A., Jurado, N., NunezCalvet, M., Artigas, F., Celada, P., 2016. Phencyclidine-induced disruption of oscillatory activity in prefrontal cortex: Effects of antipsychotic drugs and receptor ligands. Eur Neuropsychopharmacol 26, 614-625.

Mayberg, H. S., Lozano, A. M., Voon, V., McNeely, H. E., Seminowicz, D., Hamani, C., Schwalb, J. M., Kennedy, S. H., 2005. Deep brain stimulation for treatment-resistant depression. Neuron 45, 651660.

McKenna, D. J., 2004. Clinical investigations of the therapeutic potential of ayahuasca: rationale and regulatory challenges. Pharmacol Ther 102, 111-129. 
McKenna, D. J., Peroutka, S. J., 1989. Differentiation of 5-hydroxytryptamine2 receptor subtypes using 125I-R-(-)2,5-dimethoxy-4-iodo-phenylisopropylamine and 3H-ketanserin. J Neurosci 9, 34823490.

McKenna, D. J., Repke, D. B., Lo, L., Peroutka, S. J., 1990. Differential interactions of indolealkylamines with 5-hydroxytryptamine receptor subtypes. Neuropharmacology 29, 193-198.

Monteggia, L. M., Zarate, C., Jr., 2015. Antidepressant actions of ketamine: from molecular mechanisms to clinical practice. Curr Opin Neurobiol 30, 139-143.

Moreau, A. W., Amar, M., Le Roux, N., Morel, N., Fossier, P., 2010. Serotoninergic fine-tuning of the excitation-inhibition balance in rat visual cortical networks. Cereb Cortex 20, 456-467.

Murck, H., Frieboes, R. M., Antonijevic, I. A., Steiger, A., 2001. Distinct temporal pattern of the effects of the combined serotonin-reuptake inhibitor and 5-HT1A agonist EMD 68843 on the sleep EEG in healthy men. Psychopharmacology (Berl) 155, 187-192.

Muthukumaraswamy, S. D., Carhart-Harris, R. L., Moran, R. J., Brookes, M. J., Williams, T. M., Errtizoe, D., Sessa, B., Papadopoulos, A., Bolstridge, M., Singh, K. D., Feilding, A., Friston, K. J., Nutt, D. J., 2013. Broadband cortical desynchronization underlies the human psychedelic state. J Neurosci 33, 15171-15183.

Nichols, D. E., 2004. Hallucinogens. Pharmacol Ther 101, 131-181.

Palenicek, T., Fujakova, M., Brunovsky, M., Balikova, M., Horacek, J., Gorman, I., Tyls, F., Tislerova, B., Sos, P., Bubenikova-Valesova, V., Hoschl, C., Krajca, V., 2011. Electroencephalographic spectral and coherence analysis of ketamine in rats: correlation with behavioral effects and pharmacokinetics. Neuropsychobiology 63, 202-218.

Palhano-Fontes, F., Andrade, K. C., Tofoli, L. F., Santos, A. C., Crippa, J. A., Hallak, J. E., Ribeiro, S., de Araujo, D. B., 2015. The psychedelic state induced by ayahuasca modulates the activity and connectivity of the default mode network. PLoS One 10, e0118143.

Pompeiano, M., Palacios, J. M., Mengod, G., 1992. Distribution and cellular localization of mRNA coding for 5-HT1A receptor in the rat brain: correlation with receptor binding. J Neurosci 12, 440453.

Pompeiano, M., Palacios, J. M., Mengod, G., 1994. Distribution of the serotonin 5-HT2 receptor family mRNAs: comparison between 5-HT2A and 5-HT2C receptors. Brain Res Mol Brain Res 23, 163178.

Puig, M. V., Artigas, F., Celada, P., 2005. Modulation of the activity of pyramidal neurons in rat prefrontal cortex by raphe stimulation in vivo: involvement of serotonin and GABA. Cereb Cortex 15, 1-14.

Puig, M. V., Gener, T., 2015. Serotonin Modulation of Prefronto-Hippocampal Rhythms in Health and Disease. ACS Chem Neurosci 6, 1017-1025.

Raichle, M. E., MacLeod, A. M., Snyder, A. Z., Powers, W. J., Gusnard, D. A., Shulman, G. L., 2001. A default mode of brain function. Proc Natl Acad Sci U S A 98, 676-682.

Rappelsberger, P., Petsche, H., 1988. Probability mapping: power and coherence analyses of cognitive processes. Brain Topogr 1, 46-54.

Riba, J., Anderer, P., Jane, F., Saletu, B., Barbanoj, M. J., 2004. Effects of the South American psychoactive beverage ayahuasca on regional brain electrical activity in humans: a functional neuroimaging study using low-resolution electromagnetic tomography. Neuropsychobiology 50, 89101.

Riba, J., Anderer, P., Morte, A., Urbano, G., Jane, F., Saletu, B., Barbanoj, M. J., 2002. Topographic pharmaco-EEG mapping of the effects of the South American psychoactive beverage ayahuasca in healthy volunteers. Br J Clin Pharmacol 53, 613-628. 
Riga, M. S., Bortolozzi, A., Campa, L., Artigas, F., Celada, P., 2016. The serotonergic hallucinogen 5methoxy-N,N-dimethyltryptamine disrupts cortical activity in a regionally-selective manner via 5$\mathrm{HT}(1 \mathrm{~A})$ and 5-HT(2A) receptors. Neuropharmacology 101, 370-378.

Riga, M. S., Soria, G., Tudela, R., Artigas, F., Celada, P., 2014. The natural hallucinogen 5-MeO-DMT, component of Ayahuasca, disrupts cortical function in rats: reversal by antipsychotic drugs. Int $J$ Neuropsychopharmacol 17, 1269-1282.

Sanches, R. F., de Lima Osorio, F., Dos Santos, R. G., Macedo, L. R., Maia-de-Oliveira, J. P., WichertAna, L., de Araujo, D. B., Riba, J., Crippa, J. A., Hallak, J. E., 2016. Antidepressant Effects of a Single Dose of Ayahuasca in Patients With Recurrent Depression: A SPECT Study. J Clin Psychopharmacol 36, 77-81.

Santana, N., Bortolozzi, A., Serrats, J., Mengod, G., Artigas, F., 2004. Expression of serotonin1A and serotonin2A receptors in pyramidal and GABAergic neurons of the rat prefrontal cortex. Cereb Cortex 14, 1100-1109.

Sarnthein, J., Petsche, H., Rappelsberger, P., Shaw, G. L., von Stein, A., 1998. Synchronization between prefrontal and posterior association cortex during human working memory. Proc Natl Acad Sci U S A 95, 7092-7096.

Saulin, A., Savli, M., Lanzenberger, R., 2012. Serotonin and molecular neuroimaging in humans using PET. Amino Acids 42, 2039-2057.

Scheidegger, M., Walter, M., Lehmann, M., Metzger, C., Grimm, S., Boeker, H., Boesiger, P., Henning, A., Seifritz, E., 2012. Ketamine decreases resting state functional network connectivity in healthy subjects: implications for antidepressant drug action. PLoS One 7, e44799.

Seifritz, E., Moore, P., Trachsel, L., Bhatti, T., Stahl, S. M., Gillin, J. C., 1996. The 5-HT1A agonist ipsapirone enhances EEG slow wave activity in human sleep and produces a power spectrum similar to 5-HT2 blockade. Neurosci Lett 209, 41-44.

Seymour, K., Stein, T., Sanders, L. L., Guggenmos, M., Theophil, I., Sterzer, P., 2013. Altered contextual modulation of primary visual cortex responses in schizophrenia. Neuropsychopharmacology 38, 2607-2612.

Sheline, Y. I., Barch, D. M., Price, J. L., Rundle, M. M., Vaishnavi, S. N., Snyder, A. Z., Mintun, M. A., Wang, S., Coalson, R. S., Raichle, M. E., 2009. The default mode network and self-referential processes in depression. Proc Natl Acad Sci U S A 106, 1942-1947.

Shen, H. W., Jiang, X. L., Winter, J. C., Yu, A. M., 2010. Psychedelic 5-methoxy-N,Ndimethyltryptamine: metabolism, pharmacokinetics, drug interactions, and pharmacological actions. Curr Drug Metab 11, 659-666.

Shen, H. W., Jiang, X. L., Yu, A. M., 2011. Nonlinear pharmacokinetics of 5-methoxy-N,Ndimethyltryptamine in mice. Drug Metab Dispos 39, 1227-1234.

Sills, M. A., Wolfe, B. B., Frazer, A., 1984. Determination of selective and nonselective compounds for the 5-HT 1A and 5-HT 1B receptor subtypes in rat frontal cortex. J Pharmacol Exp Ther 231, 480487.

Sood, A., Jones, D. T., 2013. On mind wandering, attention, brain networks, and meditation. Explore (NY) 9, 136-141.

Steriade, M., 2006. Grouping of brain rhythms in corticothalamic systems. Neuroscience 137, 10871106.

Tagliazucchi, E., Roseman, L., Kaelen, M., Orban, C., Muthukumaraswamy, S. D., Murphy, K., Laufs, H., Leech, R., McGonigle, J., Crossley, N., Bullmore, E., Williams, T., Bolstridge, M., Feilding, A., Nutt, D. J., Carhart-Harris, R., 2016. Increased Global Functional Connectivity Correlates with LSD-Induced Ego Dissolution. Curr Biol 26, 1043-1050.

Tissier, M. H., Lainey, E., Fattaccini, C. M., Hamon, M., Adrien, J., 1993. Effects of ipsapirone, a 5HT1A agonist, on sleep/wakefulness cycles: probable post-synaptic action. J Sleep Res 2, 103-109. 
Tricklebank, M. D., Forler, C., Middlemiss, D. N., Fozard, J. R., 1985. Subtypes of the 5-HT receptor mediating the behavioural responses to 5-methoxy- $\mathrm{N}, \mathrm{N}$-dimethyltryptamine in the rat. Eur $\mathrm{J}$ Pharmacol 117, 15-24.

Uhlhaas, P. J., Singer, W., 2010. Abnormal neural oscillations and synchrony in schizophrenia. Nat Rev Neurosci 11, 100-113.

Valle, M., Maqueda, A. E., Rabella, M., Rodriguez-Pujadas, A., Antonijoan, R. M., Romero, S., Alonso, J. F., Mananas, M. A., Barker, S., Friedlander, P., Feilding, A., Riba, J., 2016. Inhibition of alpha oscillations through serotonin-2A receptor activation underlies the visual effects of ayahuasca in humans. Eur Neuropsychopharmacol 26, 1161-1175.

van den Buuse, M., Ruimschotel, E., Martin, S., Risbrough, V. B., Halberstadt, A. L., 2011. Enhanced effects of amphetamine but reduced effects of the hallucinogen, 5-MeO-DMT, on locomotor activity in 5-HT(1A) receptor knockout mice: implications for schizophrenia. Neuropharmacology 61, 209216.

Vollenweider, F. X., Kometer, M., 2010. The neurobiology of psychedelic drugs: implications for the treatment of mood disorders. Nat Rev Neurosci 11, 642-651.

Vollenweider, F. X., Leenders, K. L., Scharfetter, C., Maguire, P., Stadelmann, O., Angst, J., 1997. Positron emission tomography and fluorodeoxyglucose studies of metabolic hyperfrontality and psychopathology in the psilocybin model of psychosis. Neuropsychopharmacology 16, 357-372.

Vollenweider, F. X., Vollenweider-Scherpenhuyzen, M. F., Babler, A., Vogel, H., Hell, D., 1998. Psilocybin induces schizophrenia-like psychosis in humans via a serotonin-2 agonist action. Neuroreport 9, 3897-3902.

Watakabe, A., Komatsu, Y., Sadakane, O., Shimegi, S., Takahata, T., Higo, N., Tochitani, S., Hashikawa, T., Naito, T., Osaki, H., Sakamoto, H., Okamoto, M., Ishikawa, A., Hara, S., Akasaki, T., Sato, H., Yamamori, T., 2009. Enriched expression of serotonin 1B and 2A receptor genes in macaque visual cortex and their bidirectional modulatory effects on neuronal responses. Cereb Cortex 19, 1915-1928.

Weible, A. P., Piscopo, D. M., Rothbart, M. K., Posner, M. I., Niell, C. M., 2017. Rhythmic brain stimulation reduces anxiety-related behavior in a mouse model based on meditation training. Proc Natl Acad Sci U S A 114, 2532-2537.

Winter, J. C., Filipink, R. A., Timineri, D., Helsley, S. E., Rabin, R. A., 2000. The paradox of 5-methoxy$\mathrm{N}, \mathrm{N}$-dimethyltryptamine: an indoleamine hallucinogen that induces stimulus control via 5-HT1A receptors. Pharmacol Biochem Behav 65, 75-82.

Wood, J., Kim, Y., Moghaddam, B., 2012. Disruption of prefrontal cortex large scale neuronal activity by different classes of psychotomimetic drugs. J Neurosci 32, 3022-3031.

Zarate, C. A., Jr., Singh, J. B., Carlson, P. J., Brutsche, N. E., Ameli, R., Luckenbaugh, D. A., Charney, D. S., Manji, H. K., 2006. A randomized trial of an N-methyl-D-aspartate antagonist in treatmentresistant major depression. Arch Gen Psychiatry 63, 856-864. 


\section{Figures}

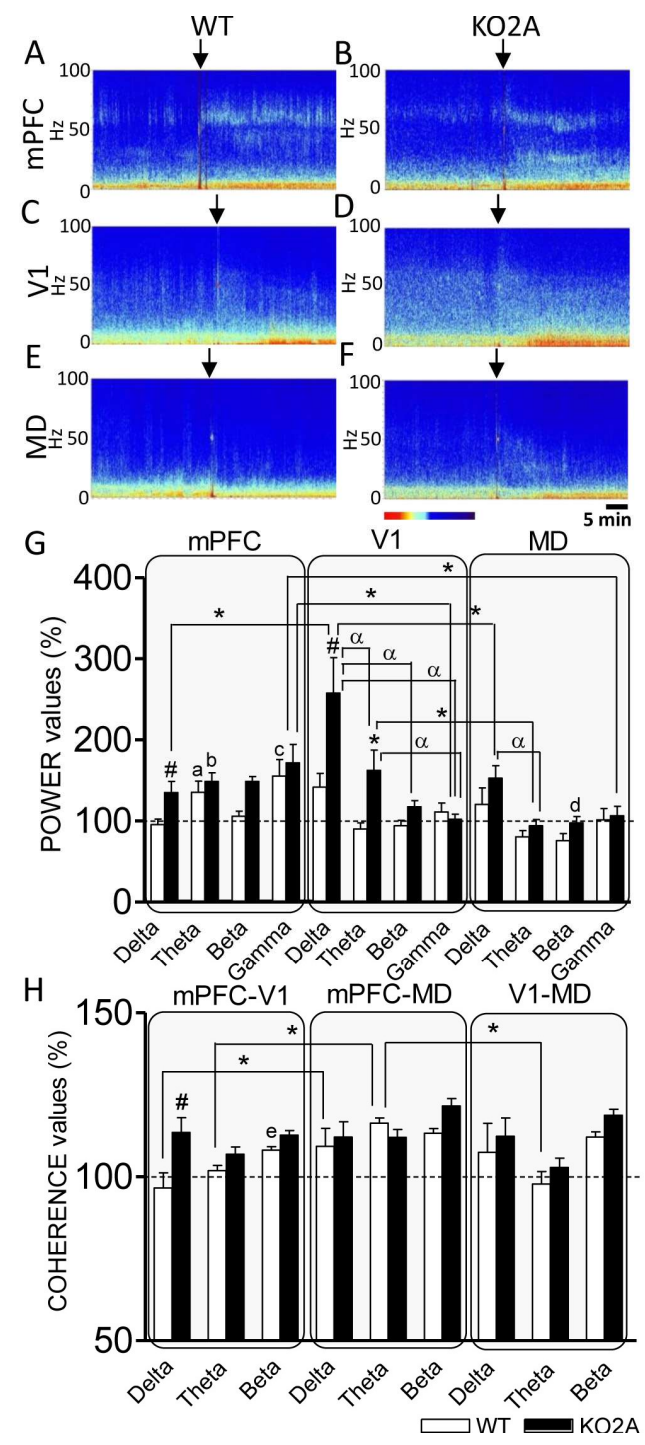

Figure 1. Effect of 5-MeO-DMT (5 mg/kg s.c.) on the power of delta, theta, beta and gamma oscillations in medial prefrontal cortex (mPFC), primary visual cortex (V1) and mediodorsal thalamus (MD) of freely-moving wild-type (WT) mice during 30 minute post-administration. Mice treated with 5-MeO-DMT received saline 30 min before active drug (SAL + 5-MeO-DMT; filled symbols). Control groups for each genotype received two saline injections (SAL + SAL; open symbols). First and second arrows indicate SAL and SAL or 5-MeO-DMT, respectively. Data are given as percentage of saline values (administered 30 minutes before 5-MeO-DMT injection) in 5-min periods. Injection periods (5 minutes post- 1 st and 2 nd injections) were excluded from the calculations. Rectangles indicate significant 5-MeO-DMT effects (versus 30-minutes pre-drug administration values). Data shown in Table 1. 
Delta
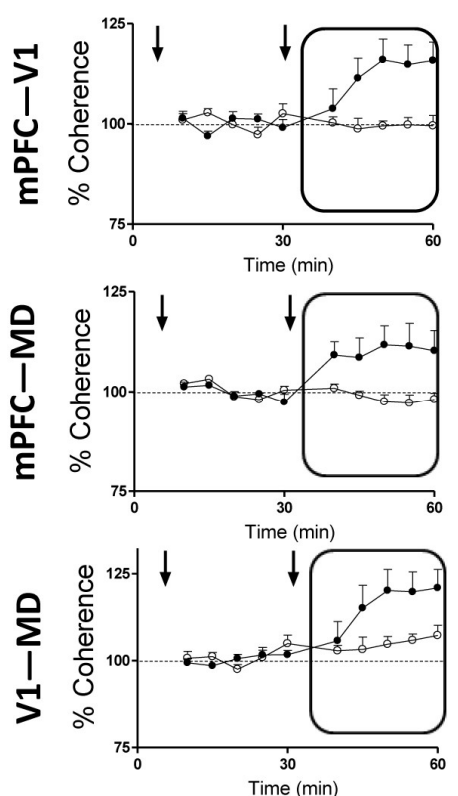

Theta
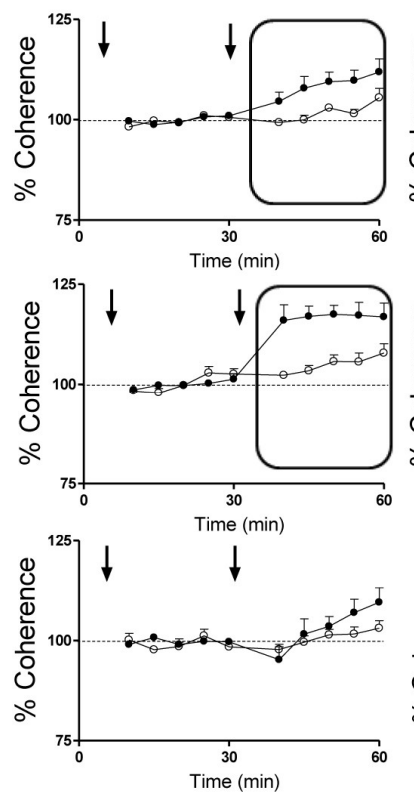

Beta
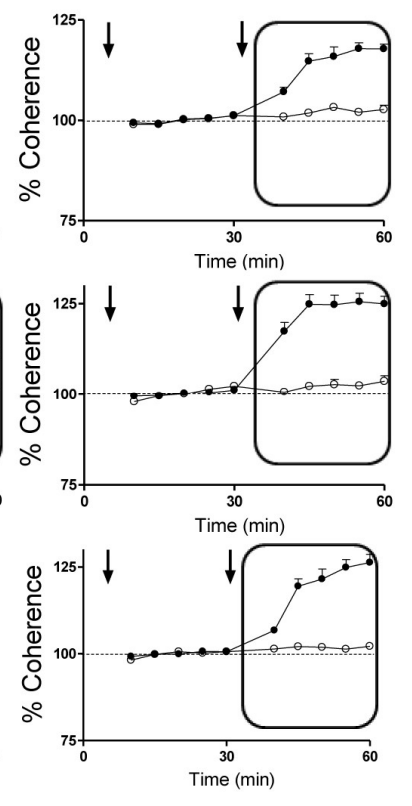

$\rightarrow$ KO2A SAL +SAL $\rightarrow$ KO2A SAL+5-MeO-DMT

Figure 2. Effect of 5-MeO-DMT on the coherence between areas (primary visual cortex, V1; mediodorsal thalamus, MD; medial prefrontal cortex, $\mathrm{mPFC}$ ) for the delta, theta and beta bands in freely-moving wild-type (WT) mice during 30 minute post-administration. Mice treated with 5-MeO-DMT received saline $30 \mathrm{~min}$ before active drug (SAL + 5-MeO-DMT; filled symbols). Control groups for each genotype received two saline injections (SAL + SAL; open symbols). First and second arrows indicate SAL and SAL or 5-MeO-DMT, respectively. Data are given as percentage of saline values (administered 30 minutes before 5-MeO-DMT injection) in 5-min periods. Injection periods (5 minutes post- 1 st and 2 nd injections) were excluded from the calculations. Rectangles indicate significant 5-MeO-DMT effects (versus 30-minutes pre-drug administration values). Data shown in Table 1. 

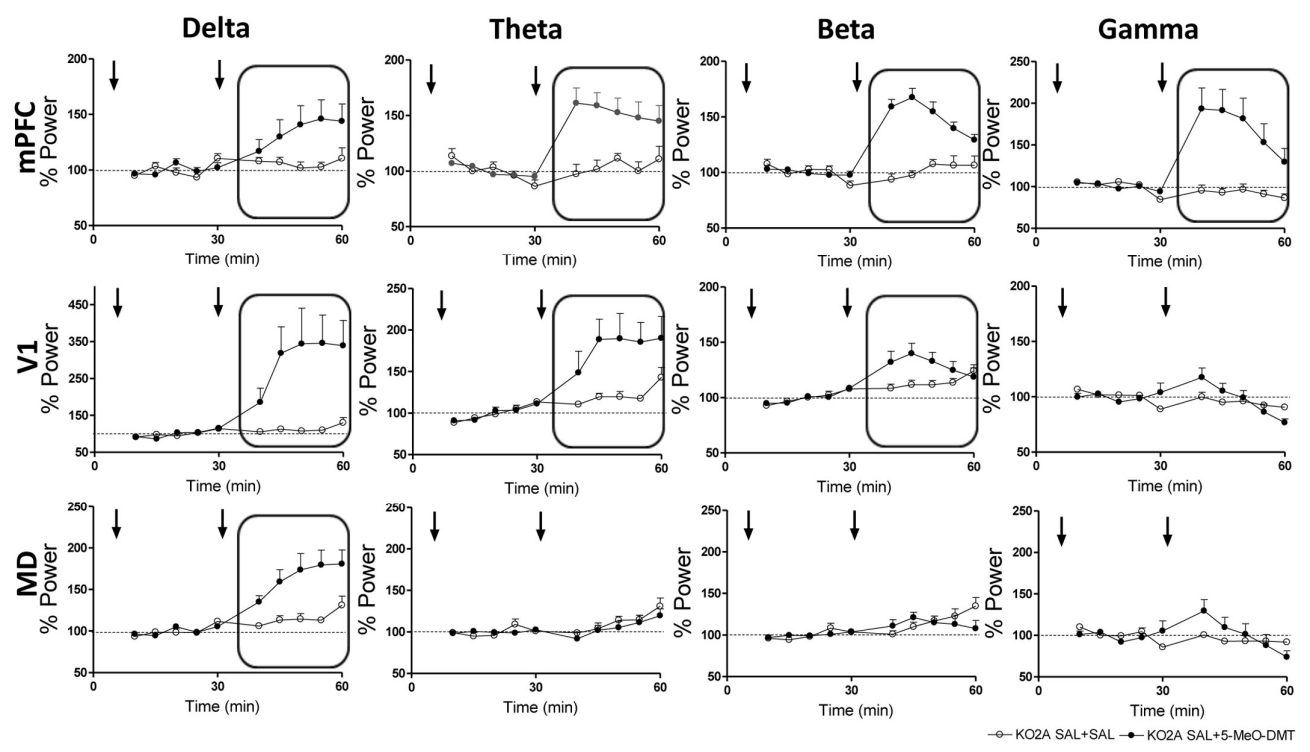

Figure 3. The atypical antipsychotic drug risperidone (RIS, $5-H T_{2 A} / D_{2}-R$ antagonist) prevent 5-MeO-DMT effects in a regionally-selective manner on band powers (A-D) and interregional coherences (E-H) in wild type (WT) mice. Mice are pretreated with saline (SAL) or RIS. Data are shown in \% of areas under curve of SAL or RIS (pretreatments) values. Rectangles show significant preventions. Note that RIS prevents 5-MeO-DMT effect only in mPFC-theta and in MPFC-MD coherence in theta and beta bands.

Statistical analysis: Two-way ANOVA (treatment and time as factors) (see Supplementary Table S3A). Statistical significance: ${ }^{*} p<0.05$ versus $1^{\text {st }}$ s.c. injection values; ${ }^{\#} p<0.05$ versus saline values; ${ }^{\&} p<0.05$ versus $\mathrm{SAL}+5-\mathrm{MeO}-\mathrm{DMT}$ values; ${ }^{\mathrm{a}} \mathrm{p}=0.053$ (marginally significant) versus $1^{\text {st }}$ s.c. injection values. In $\mathrm{mPFC}, \mathrm{V} 1$ and in mPFC-V1 coherence $n=13,10,10$ and 8 for SAL + SAL, SAL + 5-MeO-DMT, RIS + 5-MeO-DMT and RIS + SAL, respectively; In MD and in mPFC-MD and V1-MD coherences $n=8,5,6,4$ in MD for SAL + SAL, SAL + 5-MeODMT, RIS + 5-MeO-DMT and RIS + SAL, respectively. 


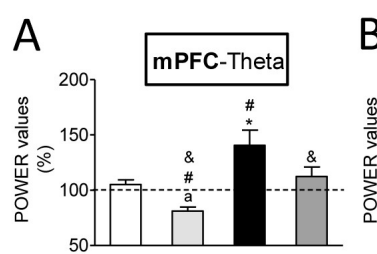

B
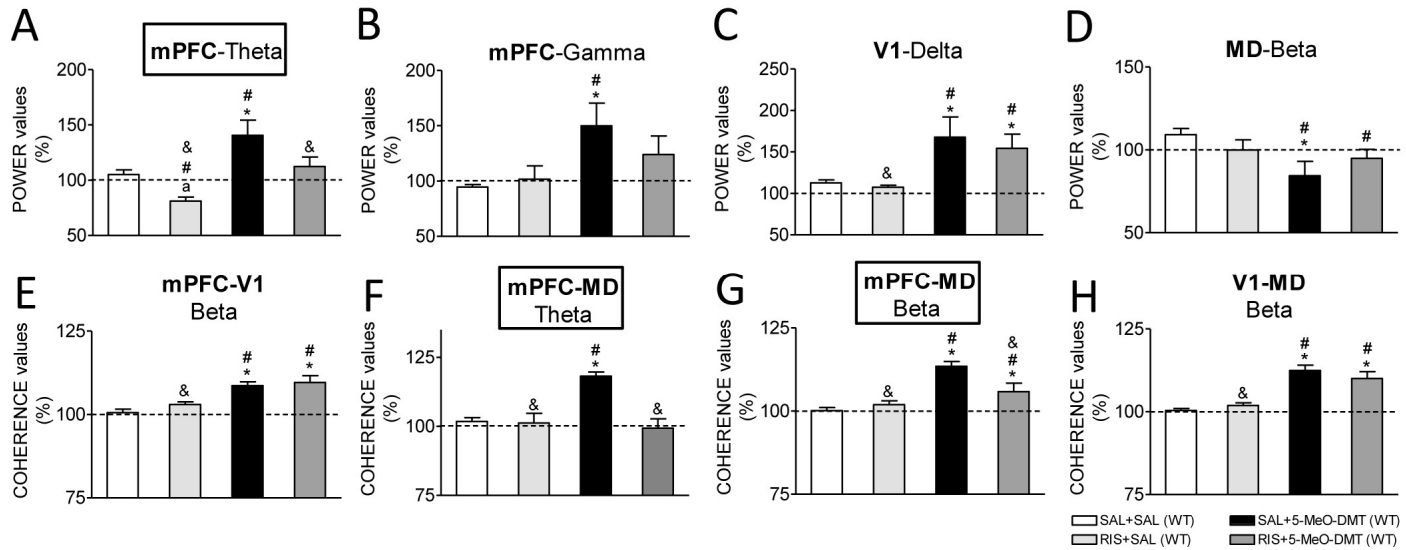

Figure 4. Effect of 5-MeO-DMT ( $5 \mathrm{mg} / \mathrm{kg}$ s.c.) on the power of delta, theta, beta and gamma oscillations in medial prefrontal cortex (mPFC), primary visual cortex (V1) and mediodorsal thalamus (MD) of freely-moving $5-\mathrm{HT}_{2 \mathrm{~A}}-\mathrm{R}$ know-out (KO2A) mice during 30 minute post-administration. Mice treated with 5-MeO-DMT received saline $30 \mathrm{~min}$ before active drug (SAL + 5-MeO-DMT; filled symbols). Control groups for each genotype received two saline injections (SAL + SAL; open symbols). First and second arrows indicate SAL and SAL or 5-MeO-DMT, respectively. Data are given as percentage of saline values (administered 30 minutes before 5-MeO-DMT injection) in 5-min periods. Injection periods (5 minutes post- 1 st and 2 nd injections) were excluded from the calculations. Rectangles indicate significant 5-MeO-DMT effects (versus 30-minutes predrug administration values). Data shown in Table 1. 

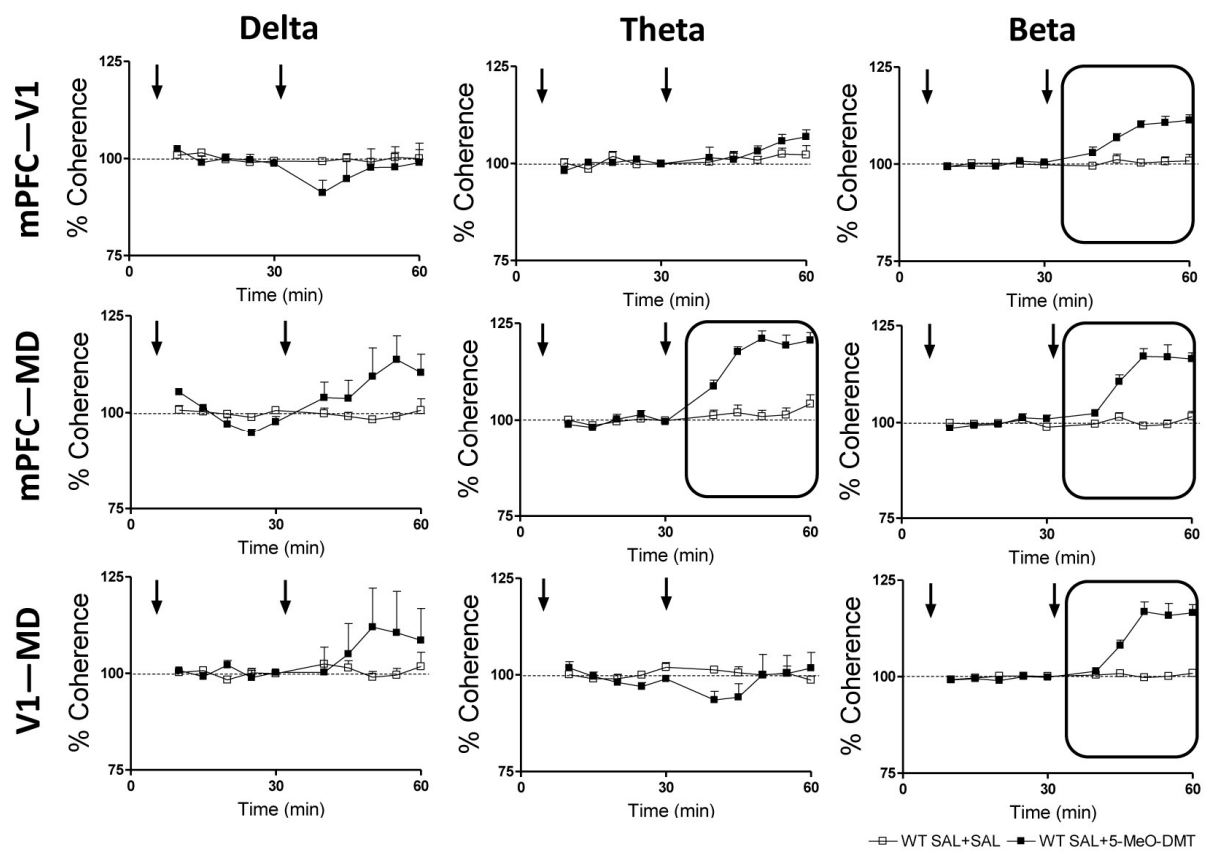

Figure 5. Effect of 5-MeO-DMT on the coherence between areas (primary visual cortex, V1; mediodorsal thalamus, MD; medial prefrontal cortex, $\mathrm{mPFC}$ ) for the delta, theta and beta bands in freely-moving $5-\mathrm{HT}_{2 \mathrm{~A}}-\mathrm{R}$ know-out (KO2A) mice during 30 minute post-administration. Mice treated with 5-MeO-DMT received saline $30 \mathrm{~min}$ before active drug (SAL + 5-MeO-DMT; filled symbols). Control groups for each genotype received two saline injections (SAL + SAL; open symbols). First and second arrows indicate SAL and SAL or 5-MeO-DMT, respectively. Data are given as percentage of saline values (administered 30 minutes before 5-MeO-DMT injection) in 5-min periods. Injection periods (5 minutes post- 1 st and 2 nd injections) were excluded from the calculations. Rectangles indicate significant 5-MeO-DMT effects (versus 30-minutes pre-drug administration values). Data shown in Table 1. 

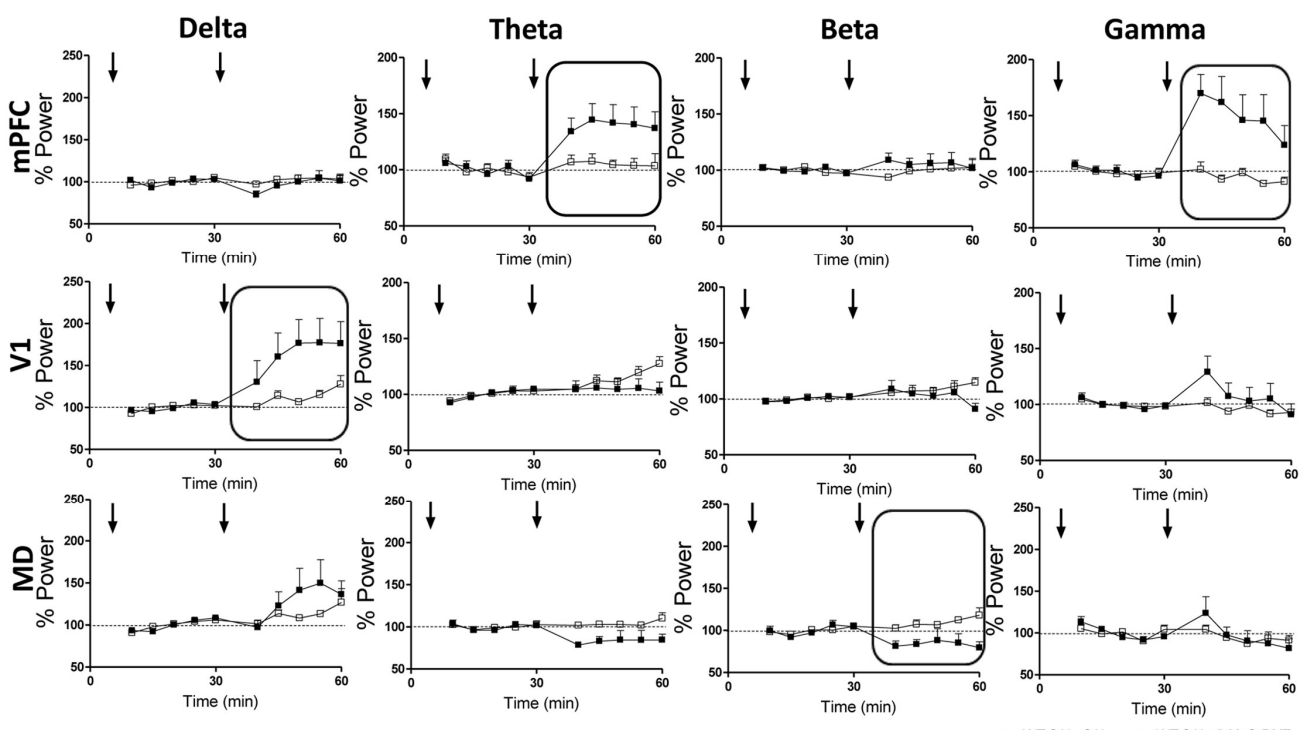

Figure 6. Effects of 5-MeO-DMT ( $5 \mathrm{mg} / \mathrm{kg}$ s.c.) on oscillatory activity (power spectra and inter-area coherences) in medial prefrontal cortex (mPFC), primary visual cortex (V1) and mediodorsal thalamus (MD). Spectrograms (A-F) show the action of 5-MeO-DMT on MPFC, V1 and MD in WT and KO2A mice. The intensity of the power spectra is color-coded (red = high intensity; blue = low intensity). The effect of 5-MeO-DMT is analyzed during 30-minutes post-administration (arrows), excluding the first 5-min period. (G, H) Bar graphs showing the effect of 5-MeO-DMT on power spectra $(\mathbf{G})$ and coherences $(\mathbf{H})$ for the two genotypes in the areas and band frequencies analyzed. All mice are pretreated with s.c. saline. The effect of vehicle was subtracted from the effect of 5-MeO-DMT. Note that i) maximal effect of 5-MeO-DMT on power spectra was produced is in V1 delta band of KO2A mice, and ii) maximal effect on coherence was on mPFC-MD coherence.

Statistical analysis: Three-way ANOVA (genotype, area or coherence and band as factors) (See Supplementary Table S3B). Statistical significance: ${ }^{*} \mathrm{p}<0.05 ;{ }^{\#} \mathrm{p}<0.05$ versus WT in the same area; ${ }^{\alpha} \mathrm{p}<0.05 ;{ }^{a} \mathrm{p}=0.055$ versus MD theta in WT mice; ${ }^{b} p=0.058$ versus MD theta in KO2A mice; ${ }^{c} p=0.060$ versus MD gamma in WT mice; $d$ $p=0.054$ versus MD delta in KO2A mice; ${ }^{e} p=0.059$ versus mPFC-V1 delta in WT mice. Power spectra (G): $n=10$ and 9 for mPFC /V1 in WT and KO2A mice, respectively; $\mathrm{n}=5$ and 9 for MD in WT and KO2A mice, respectively. Coherences $(\mathbf{H}): \mathrm{n}=10$ and 9 for mPFC-V1 in WT and KO2A mice, respectively; $\mathrm{n}=5$ and 9 for mPFC-MD/V1-MD in WT and KO2A mice, respectively. 

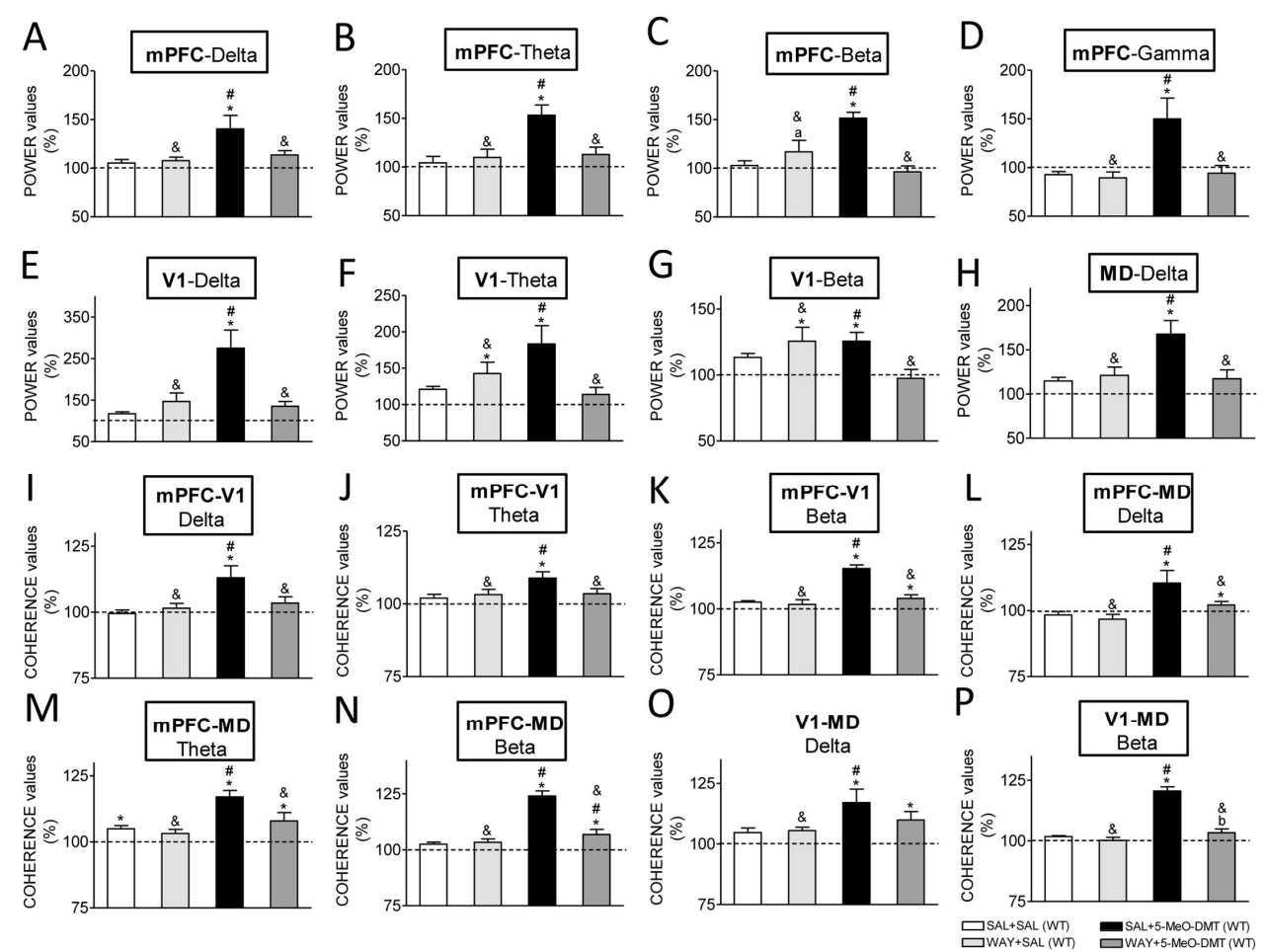

Figure 7. The 5-HT $1 \mathrm{~A}-\mathrm{R}$ antagonist WAY-100635 (WAY) prevent 5-MeO-DMT effects in a regionally-selective manner on power spectra (A-H) and coherences (I-P) between medial prefrontal cortex (mPFC), primary visual cortex (V1) and mediodorsal thalamus (MD) of 5- $\mathrm{HT}_{2 \mathrm{~A}}-\mathrm{R}$ knock-out (KO2A) mice. Mice are pretreated with saline (SAL) and WAY. Data are shown in \% of areas under curve of SAL or WAY (pretreatments) values. Rectangles show significant preventions. Note that WAY avoids all of 5-MeO-DMT effects (except in delta V1MD coherence) despite areas or bands analyzed.

Statistical analysis: Two-way ANOVA (treatment and time as factors) (see Supplementary Table S2C). Statistical significance: * $p<0.05$ versus $1^{\text {st }}$ s.c. injection values; ${ }^{\#} p<0.05$ versus saline values; ${ }^{*} p<0.05$ versus $S A L+5$ MeO-DMT values; ${ }^{\mathrm{a}} \mathrm{p}=0.050$ and ${ }^{\mathrm{b}} \mathrm{p}=0.057$ (marginally significant) versus $1^{\text {st }}$ s.c. injection values. In $\mathrm{mPFC}, \mathrm{V} 1$ and mPFC-V1 coherence $n=7,9,8$ and 8 for SAL + SAL, SAL + 5-MeO-DMT, WAY + 5-MeO-DMT and WAY + SAL, respectively; In MD and mPFC-MD and V1-MD coherences $n=6,9,7,8$ for SAL + SAL, SAL + 5-MeO-DMT, WAY + 5-MeO-DMT and WAY + SAL, respectively . 


\section{Tables}

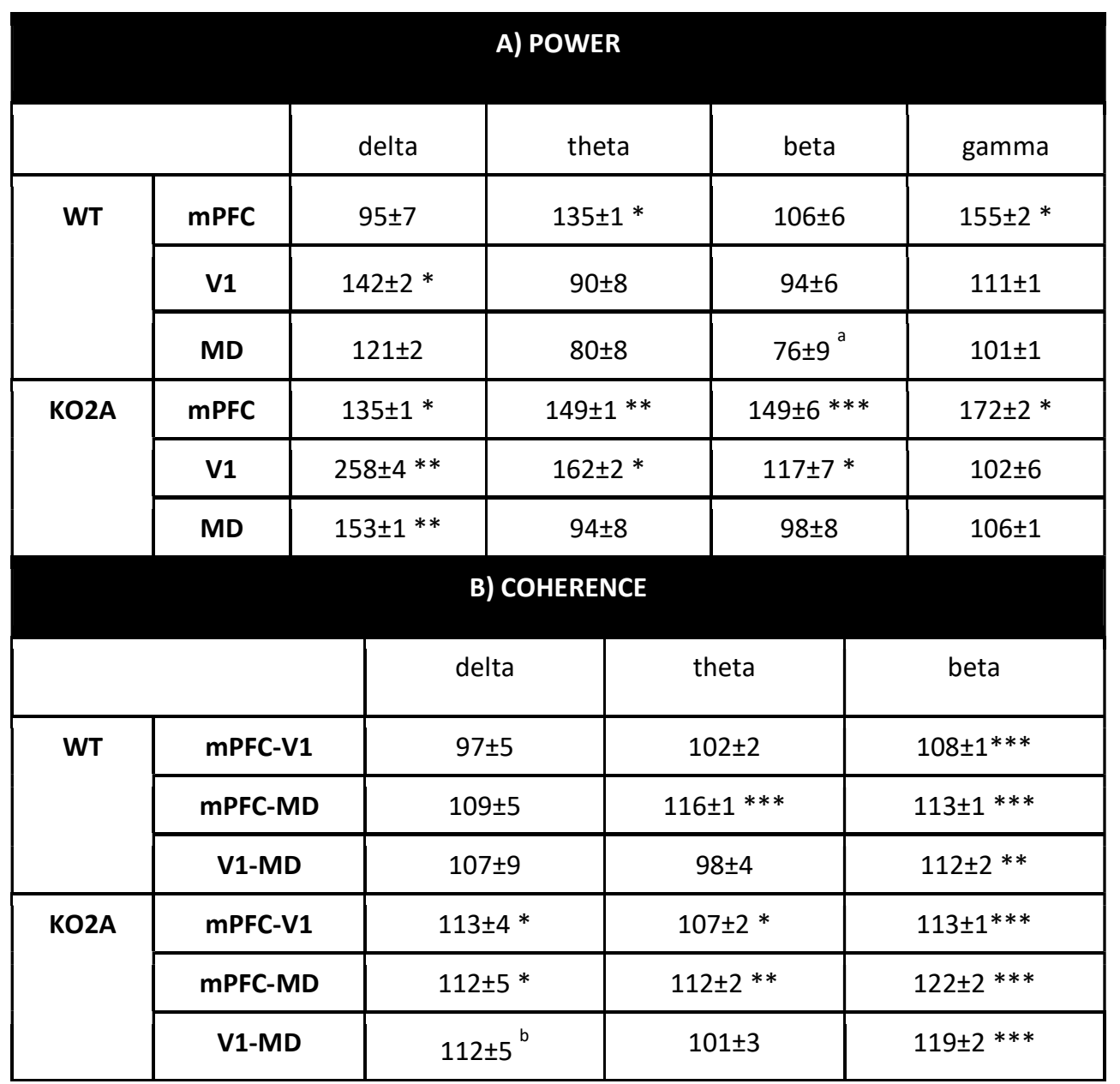

Table 1. Effect of 5-MeO-DMT administration on medial prefrontal cortex (mPFC), primary visual cortex (V1) and mediodorsal thalamus (MD) power spectra (A) and coherences between each area (B) in wild type (WT) and $5-\mathrm{HT}_{2 \mathrm{~A}}-\mathrm{R}$ know-out (KO2A) mice. Data are represented as Mean $\pm \mathrm{SEM}$ of $\%$ of change of areas under curves 5-MeO-DMT versus 30 minutes pre-drug administration values (POWER and COHERENCE values (\%)). Saline effect was substracted from the effect of 5-MeO-DMT. Note that 5-MeO-DMT effects on power spectra are more marked in cortical areas than MD thalamus nucleus. On the other hand, 5-MeO-DMT affects all coherences in delta only in KO2A while in theta only mPFC-V1 (in KO2A) and mPFC-MD (in WT and KO2A) coherences are altered. Curiously, all analyzed coherences in beta are disrupted by 5-MeO-DMT regardless of genotype.

Statistical analysis: Student's t tests for dependent samples; Statistical significance: ${ }^{*} p<0.05, * * p<0.01, * * *$ $p<0.001$ versus 30 minutes pre-drug administration values; ${ }^{a} p=0.052,{ }^{b} p=0.059$ (marginally significant); A) 
$\mathrm{n}=10$ and 9 for mPFC /V1 in WT and KO2A mice, respectively; $\mathrm{n}=5$ and 9 for MD in WT and KO2A mice, respectively; B) $n=10$ and 9 for $m$ PFC-V1 coherence in WT and KO2A mice, respectively; $n=5$ and 9 for mPFC$\mathrm{MD} / \mathrm{V1}-\mathrm{MD}$ coherences in $\mathrm{WT}$ and KO2A, respectively. 